\title{
Development and validation of a storm surge forecasting/ hindcasting modelling system for the extensive Río de la Plata Estuary and its adjacent Continental Shelf
}

\author{
Matías G. Dinápoli ${ }^{1,2,3}$ (D) Claudia G. Simionato ${ }^{1,2,3,4} \cdot$ Diego Moreira $^{1,2,3,4}$
}

Received: 24 December 2019 / Accepted: 18 May 2020

(c) Springer Nature B.V. 2020

\begin{abstract}
The Río de la Plata (RdP) Estuary is affected by significant surges several times per year. This phenomenon has historically caused catastrophic water-level enlargements of up to $4.44 \mathrm{~m}$, threatening and claiming human lives and producing major economic and material damages. The negative surges are less frequent, but when they do occur, inhibit the access to the principal harbors and waterways and disable the drinking water intakes of the Metropolitan Area of Buenos Aires (the Capital City of Argentina) with a population of more and 16 million people. Recent works suggest that the number and strength of the surge events have been increasing with time. Nevertheless, a state-of-the-art system for the forecast of those events is not available yet. In this work, the implementation of a numerical modelling system for the forecast/hindcast of storm surges and the associated currents in the RdP and the adjacent continental shelf are presented and validated. This pre-operational system is based on an adaptation of the CROCO community ocean model to solve the dynamics associated with the surge. The model was implemented using a set of routines written in open-source programming language (Linux and Python) to be cheap and efficient and to ensure an easy future transfer to the services responsible for the alerts. For a better representation of the regional atmospheric dynamics, wind speed and sea-level pressure used to force the simulations were corrected using direct observations collected at an oceanographic buoy anchored at the estuary. The model system performance in hindcast mode was quantified by comparison with observations from tidal gauges and current meters at several locations of the estuary and the adjacent shelf. Percent errors for water level over the whole estuary and currents in the intermediate and exterior estuary drove to average results of 8 and 13\%, respectively. The skill scores resulted, on average, of 0.90 and 0.80 , respectively. The model performance in both hindcast and forecast modes was evaluated during historical extreme storm surges. Results support the good performance of the model to simulate even extreme events with average skill scores of 0.97 and 0.92 , respectively. Results are encouraging, particularly taking into account the limitations in the atmospheric forcing for the region, where only a relatively small number of direct observations are assimilated by the reanalysis and forecast models.
\end{abstract}

Keywords Pre-operational modelling system $\cdot$ Storm surges alert and forecast $\cdot$ Río de la Plata Estuary

Extended author information available on the last page of the article 


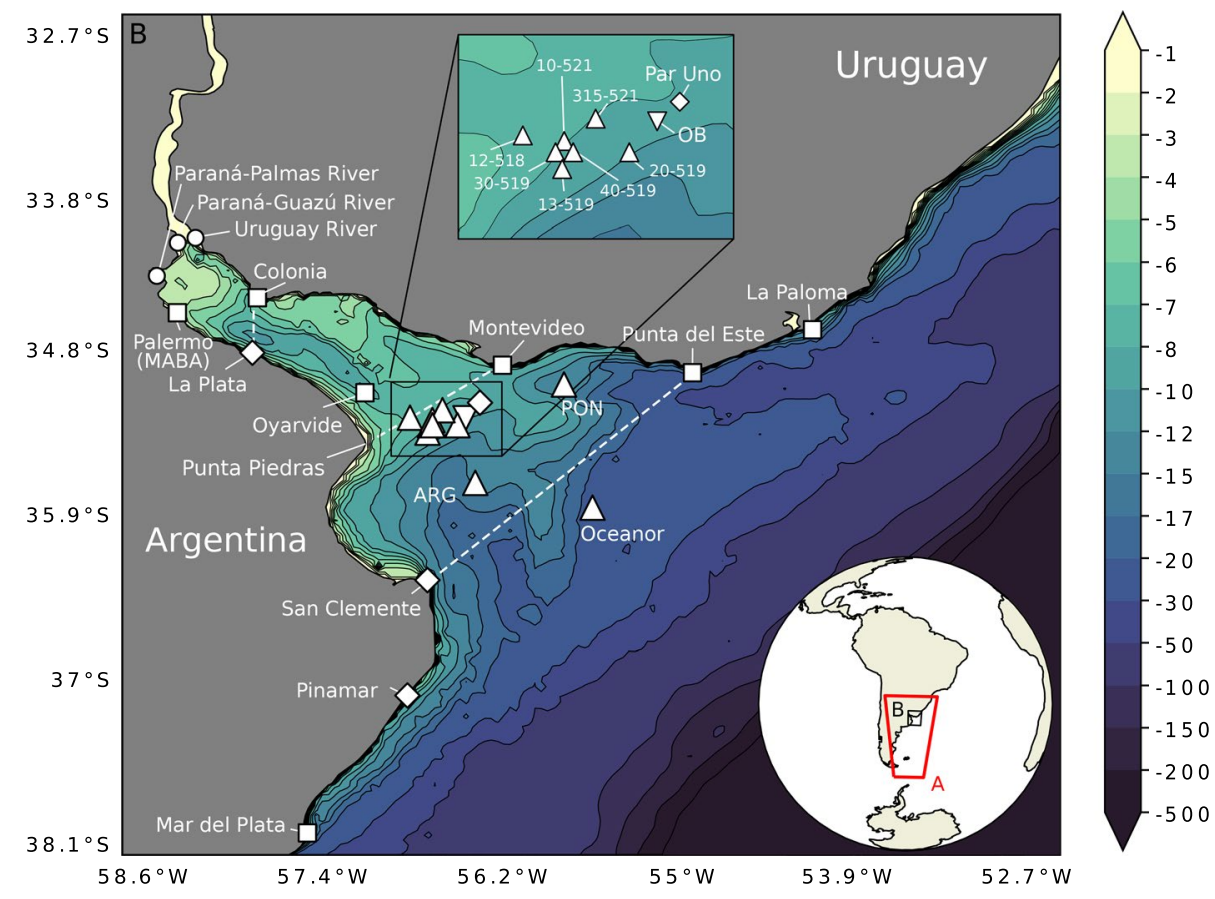

Fig. 1 Map of the study area, showing the domain of the two nested models (A and B) and location of the tidal gauges (squares), the current meters (up-triangles), the oceanographic buoy (OB, down-triangle), station with amplitude and phase of the $\mathrm{M}_{2}$ tidal constituent (diamonds) and river mouth (circles). Stroke lines indicate the division of the estuary. Isolines represent the bathymetry in meters

\section{Introduction}

The shallow Río de la Plata (RdP, Fig. 1) is one of the largest and mightiest estuaries in the world (Shiklomanov 1998). It has a funnel shape oriented from northwest to southeast, a length of around $320 \mathrm{~km}$, and widens from approximately $40 \mathrm{~km}$ at its uppermost part to $230 \mathrm{~km}$ at its mouth (Meccia et al. 2009). The estuarine area is of $35,000 \mathrm{~km}^{2}$, and the fluvial drainage area is of $3.1 \times 10^{6} \mathrm{~km}^{2}$ (Balay 1961), ranking fourth and fifth worldwide in freshwater discharge and drainage area, respectively (Framinan et al. 1999). Indeed, this estuary is the second largest basin of South America after the Amazon (Meccia et al. 2009; Santoro et al. 2011).

With a population of several millions, the RdP estuary has enormous social and economical importance. Its coasts are the site of two capital cities (Buenos Aires and Montevideo, Fig. 1) and also contain the most relevant harbors, industrial poles and resorts of southern South America (Moreira and Simionato 2019). The RdP has two important waterways, which are the main fluvial access to the cities in the north of Argentina, Uruguay and Paraguay (Meccia et al. 2009; Santoro et al. 2011). This estuary is also the main source of drinking water for the millions of inhabitants in the hinterlands (Moreira and Simionato 2019). Naturally, because the RdP is one of the most developed basins of southern South America, it is an object of large anthropogenic impact and many environmental problems and societal need to be managed in this region. 
The RdP is commonly affected by the so-called Sudestadas, associated with strong and persistent southeasterly winds that cause significant surges over the estuary several times per year (Campetella et al. 2007, and references therein). This phenomenon has historically caused catastrophic floods in the RdP coasts, threatening and claiming human lives and producing major economic and material damages (D'Onofrio et al. 1999). The Metropoli$\tan$ Area of Buenos Aires City (MABA, shown as Palermo in Fig. 1), site of the Capital of Argentina with a population of more than 16 million people, is regularly affected by those events (D'Onofrio et al. 2008). Since records began in 1905, the maximum water level at Buenos Aires was registered in 1940. During this event, enhanced by particularly strong south-easterly winds, it reached $4.44 \mathrm{~m}$ above the Tidal Datum, being the tidal height overcome by $3.48 \mathrm{~m}$ (Simionato et al. 2004b). More recently, in 1989 and 1993, extreme floods were also experienced at the city. Water levels reached $4.06 \mathrm{~m}$ and $3.95 \mathrm{~m}$ above the Tidal Datum, being $1.90 \mathrm{~m}$ the emergency alert level (Balay 1961) and the tidal heights overcome by $3.10 \mathrm{~m}$ and $2.99 \mathrm{~m}$, respectively D'Onofrio et al. (1999). On the contrary, negative extreme surges are associated with winds that have a dominant westerly to north-westerly component that are less frequent in the region (D'Onofrio et al. 2008). Nonetheless, when they do occur, the associated surge inhibits the access to the principal harbors, waterways and drinking water intakes of one of the most important cities of southern South America (Campetella et al. 2007). For instance, in 2009 a negative extreme surge event took place decreasing the water level to $-2.40 \mathrm{~m}$ under the Tidal Datum (Pousa et al. 2012). Even though the positive and negative storm surges are not always so extreme, they take place several times per year; moreover, observations suggest that the number and strength of the events have been increasing with time (D'Onofrio et al. 2008; Meccia et al. 2009).

In this context, the knowledge of the conditions of the near shore and coastal hydrodynamics are essential inputs for coastal risk management and monitoring activities in the $\mathrm{RdP}$. Information from ocean forecast models is valuable for stakeholders, decision makers and the population in general. Hindcast models, in turn, are valuable tools for understanding coastal dynamics, evaluating changes, aiding in the design of coastal defense structures and studying climate variability and change, with interest for both the scientific community and for practical purposes (WMO 2011). During the last few years, a number of highresolution ocean global models which incorporate many ocean processes and assimilate observations have been developed at several important forecast centers of the world (for instance, HYCOM, https://www.hycom.org/hycom/overview); nevertheless, only a few of them take into account the tides, which usually have large interaction with the surge (e.g., Sinha et al. 1996, at Hooghly Estuary, India; Paul et al. 2016, along the coastal of Bangladesh; Khalilabadi 2016, at the Persian Gulf, the Strait of Hormuz and the Gulf of Oman; Feng et al. 2018 at the Bohai Sea, China; Xiong et al. 2019, at the Yellow Sea; Pandey and Rao 2019, at Bay of Bengal; Sebastian et al. 2019, along the eastern coast of India; Wankang et al. 2019, at the Tieshan Bay, China; Dinápoli et al. 2020, at the Río de la Plata Estuary). Moreover, the small details of the bathymetry (fundamental on the propagation of barotropic waves and, particularly, surges) are not well resolved by those models at many coastal inlets as it is the case for the RdP (Saraceno et al. 2010). The most usual approach to provide reliable forecasts/hindcasts of sea levels (and eventually currents) at coastal areas is through the implementation of regional high-resolution barotropic models (e.g., Horsburgh and Wilson 2007; Nicolle et al. 2009; Zhang et al. 2010; WMO 2011; Idier et al. 2012; Xu et al. 2016; Hussain and Tajima 2017; Krien et al. 2017). Currently, in the frame of collaborative projects between the Centre for Atmospheric and Oceanic Research (CIMA/CONICET-UBA), the Hydrographic Service of the Navy (SHN) and the National Meteorological Service (SMN) of Argentine, the application of a storm 
surge forecast/hindcast pre-operational modelling system for the RdP and the adjacent continental shelf is being faced. For the implementation, the scientific community numerical ocean model CROCO (Coastal and Regional Ocean COmmunity Model, Debreu et al. 2012) source code was modified to a $2 \mathrm{D}$ barotropic version which can be cheaply and successfully applied to forecast/hindcast of water level and depth-averaged horizontal currents. The model was also adapted to incorporate the atmospheric surface pressure as forcing, that is omitted in CROCO and that can have a large impact on the surge (WMO 2011; Dinápoli et al. 2020). Given that the RdP is sensitive to atmospheric large scale dynamics (Simionato et al. 2006a), the model was applied to the region in a dynamic downscaling scheme of one-way nested models to take into account the coastally trapped waves that travel to the estuary along the Argentinean coast (from south to north in the Southern Hemisphere Simionato et al. 2006b). In this paper, the above-mentioned modifications and adaptation of CROCO model are presented. A validation is performed by comparing statistically the model results to direct observations of sea level and currents collected by tidal gauges and current meters at several sites of the estuary considering both normal conditions and extreme surge events. Finally, in the last section, a summary of conclusions is drawn.

\section{Study area}

The RdP estuary results of the confluence of two of the most important rivers of South America, Paraná and Uruguay (Fig. 1), are not only abundant but also transport to the estuary between 80 and 160 million tons per year of suspended sediments and a large amount of nutrients (Re et al. 2010; Re and Menéndez 2011; Sarubbi 2007). The Paraná River, with a mean runoff of $16,000 \mathrm{~m}^{3} \mathrm{~s}^{-1}$, converges to the estuary forming a large delta; its two main branches are the Paraná Guazú-Bravo River, which transports approximately $77 \%$ of the runoff, and the Paraná de las Palmas River that transports the remaining 23\% (Jaime et al. 2002). The Uruguay River has a mean runoff of $6000 \mathrm{~m}^{3} \mathrm{~s}^{-1}$ (Jaime et al. 2002). The Paraná and Uruguay rivers account for most of the continental discharge to the RdP, because the minor tributaries' transport is several orders of magnitude smaller (Framinan et al. 1999); mean runoff is, in consequence, of about $22,000 \mathrm{~m}^{3} \mathrm{~s}^{-1}$.

The water level in the RdP is usually described as the combination of a semidiurnal microtidal regimen with diurnal inequalities (D'Onofrio et al. 2012) and the wind-driven circulation (Simionato et al. 2004a, 2006a). Wind forced currents and oscillations account for approximately $75 \%$ of the variance in the frontal zone of the estuary (Simionato et al. 2005a, 2006a, 2007). The barotropic response, associated with the surge, can be explained in terms of two modes of circulation (Simionato et al. 2004a, 2006a, 2007): (1) the prevailing one occurs for winds with a cross-estuary dominant component and is related to an inflow/outflow of water towards the Argentinean/Uruguayan coast, and (2) the second mode dominates when the wind has a dominant component blowing along the estuary axis and has a very distinctive pattern of significant water level increase or reduction at the upper part of the estuary. A particular case of this second mode is the Sudestada that occurs when strong and/or persistent southeasterly winds, which are relatively frequent, blow over the region (Seluchi and Saulo 1996; Gan and Rao 1991).

Because of its geometry and associated dynamics, the RdP can be divided into three different regions (Simionato et al. 2004a): 
- The upper part This region extends up approximately the imaginary line that connects Colonia and La Plata (Fig. 1). In this area, the water is fresh. The water level presents the maximum levels in response to winds during the surges. Nonetheless, because of its shallowness, narrowness and relatively small geographical extension, the circulation pattern has essentially a tidal river behavior, i.e., mostly dominated by tides and the continental discharge.

- The intermediate part This region spans from the limit of the upper part to the imaginary line that connects Montevideo and Punta Piedras (Fig. 1). Here, the water is mainly fresh, but the depth and the width increase and therefore the discharge current becomes weaker; here, the tides become larger and the effect of the wind is more important. This part extends to the Barra del Indio, just upstream the bottom salinity front of the RdP salt wedge (Guerrero et al. 1997).

- The outer estuary This area spans form the limit of the intermediate part to the outermost portion of the RdP, geographically defined by an imaginary line that connects Punta del Este and San Clemente (Fig. 1). This region has more oceanic characteristics, and its circulation is not only related to discharge and bathymetry but also to Earth's rotation. The area is naturally sensitive to the winds, but the response here is an oceanic Ekman type one.

\section{Data}

The sites where direct water level, currents and winds observations available at the RdP are displayed in Fig. 1, and their locations are detailed in Table 1. Water-level observations (squares in Fig. 1) were provided by the SHN of Argentina and the Servicio Oceanográfico, Hidrográfico y Meteorológico de la Armada (SOHMA) of Uruguay. Most of the time series used in this work cover the years 2002-2003, when an important international project took place on the region (Himschoot et al. 2004). Palermo and Oyarvide are the only stations with longer periods of observations, from 1905 and 1992 to present for Palermo and Oyarvide, respectively. The dash in the periods' column indicates that at those stations only amplitude and phase of the tidal constituents are available. These data were obtained from the SEAT tidal software developed by D'Onofrio et al. (2012).

Current observations (up triangles in Fig. 1) correspond to depth-averaged horizontal currents. Additionally, this dataset is divided into two sets: one of them consists of eight stations gathered at the central part of the estuary between June and September, 1996, by Hidrovía (Jan De Nul) of Argentina, a private company in charge of the maintenance of the navigation channels; the other set is composed of three instruments deployed at the exterior estuary, Oceanor spanning from December 1998 to April 1999, ARG from December 2002 to June 2003 and PON from September 2003 to April 2004. ARG and PON have one gap each during those periods, when the instruments were recovered, and the data collected and the instruments were then redeployed. For the comparison with the model solutions, the current time series were hourly sampled by linear interpolation.

Sea-level pressure, surface air density and 10-m wind data are: (1) for the hindcast, the 1-hourly ERA5 (Copernicus Climate Change Service (C3S) 2017) reanalysis; and (2) for the forecast, the 6-hourly Atmospheric Model High Resolution (HRES) 10-day. Both dataset have $0.25^{\circ}$ spatial resolution and are developed by the European Centre for Medium-Range Weather Forecast (ECMWF). Direct wind observations (speed and direction) over the water were collected at two different sites of the estuary. At the central RdP, an oceanographic buoy 
Table 1 Location of water-level gauges, current meters and the oceanographic buoys used for the validation

\begin{tabular}{|c|c|c|c|c|}
\hline Variable & Station & Longitude $\left({ }^{\circ}\right)$ & Latitude $\left(^{\circ}\right)$ & Period \\
\hline \multirow[t]{11}{*}{ Water level } & Palermo & -58.3833 & -34.5667 & 1965-01-2019-09 \\
\hline & Colonia & -57.8500 & -34.4667 & $2002-11-2003-03$ \\
\hline & La Plata & -57.8833 & -34.8333 & - \\
\hline & Oyarvide & -57.1333 & -35.1000 & 1992-01-2019-09 \\
\hline & Montevideo & -56.2167 & -34.9167 & $2002-12-2003-12$ \\
\hline & Par Uno & -56.3666 & -35.1666 & - \\
\hline & San Clemente & -56.7167 & -36.3500 & 1998-12-1999-03 \\
\hline & Punta del Este & -54.9500 & -34.9666 & 2002-12-2003-12 \\
\hline & La Paloma & -54.1500 & -34.6800 & $2002-12-2003-03$ \\
\hline & Pinamar & -56.8500 & -37.1167 & - \\
\hline & Mar del Plata & -57.5167 & -38.0333 & 2002-12-2003-03 \\
\hline \multirow[t]{11}{*}{ Current } & Hidrovía 10-521 & -56.7000 & -35.3166 & 1996-06-1996-07 \\
\hline & Hidrovía 12-518 & -56.8330 & -35.2666 & 1996-06-1996-07 \\
\hline & Hidrovía 13-519 & -56.7160 & -35.3666 & 1996-06-1996-07 \\
\hline & Hidrovía 21-521 & -56.8333 & -35.1833 & 1996-07-1996-08 \\
\hline & Hidrovía 30-519 & -56.6833 & -35.2833 & 1996-08-1996-09 \\
\hline & Hidrovía 315-521 & -56.6166 & -35.2166 & 1996-08-1996-09 \\
\hline & Hidrovía 40-519 & -56.6833 & -35.3166 & 1996-09-1996-10 \\
\hline & Hidrová 10-521 & -56.7000 & -35.3166 & 1996-06-1996-07 \\
\hline & ARG & -56.5000 & -35.6600 & 2003-09-2004-04 \\
\hline & PON & -55.8500 & -35.0300 & 2002-12-2003-06 \\
\hline & Oceanor & -55.6166 & -35.8666 & 1998-12-1999-04 \\
\hline \multirow[t]{2}{*}{ Wind } & Oceanographic buoy & -56.4000 & -35.2000 & 2009-11-2010-12 \\
\hline & Oceanor & -55.6166 & -35.8666 & 1998-12-1999-04 \\
\hline
\end{tabular}

(OB, down triangle Fig. 1) acquired data from November 2009 to December 2010. The second time series corresponds to the Oceanor buoy which collected wind measurements at the adjacent shelf, close to the exterior RdP, between December 1998 and April 1999. Since ERA-5 provides hourly solutions, both sets of observations were hourly sampled for comparison by linear interpolation.

\section{Statistical scores used for validation}

The validation of the numerical modelling system was carried out by comparing simulations to direct observations as ground truth. To statistically summarize the results of the comparison, the bias, the root mean square dispersion (RMSD), the normalized root mean square error (NRMSE), the Pearson (linear) correlation coefficient $(R)$, the linear regression slope $(P)$, the symmetric slope coefficient $(S S)$ and the Willmott model skill score $(S k)$ were computed. The mathematical expressions for each of the above-mentioned statistics are in Eq. 1-7:

$$
\text { Bias }=\bar{s}-\bar{o}
$$




$$
\begin{gathered}
R M S D^{2}=\frac{1}{N} \sum_{n=1}^{N}\left[\left(s_{n}-\bar{s}\right)-\left(o_{n}-\bar{o}\right)\right]^{2} \\
N R M S E=\frac{1}{\max (o)-\min (o)} \sqrt{\frac{1}{N} \sum_{n=1}^{N}\left(s_{n}-o_{n}\right)^{2}} \\
R^{2}=\frac{\sum_{n=1}^{N}\left(s_{n}-\bar{s}\right)\left(o_{n}-\bar{o}\right)}{\sum_{n=1}^{N}\left(s_{n}-\bar{s}\right)^{2} \sum_{n=1}^{N}\left(o_{n}-\bar{o}\right)^{2}} \\
P=\frac{\sum_{n=1}^{N}\left(s_{n}-\bar{s}\right)\left(o_{n}-\bar{o}\right)}{\sum_{n=1}^{N}\left(o_{n}-\bar{o}\right)^{2}} \\
S k=1-\frac{\sum_{n=1}^{N}\left(s_{n}-\bar{s}\right)^{2}}{\sum_{n=1}^{N}\left(o_{n}-\bar{o}\right)^{2}} \\
\sum_{n=1}^{N}\left(s_{n}-\bar{o}\right)+\left(s_{n}-o_{n}\right)^{2} \\
\left.\left.\sum_{n}-\bar{o}\right)\right]^{2}
\end{gathered}
$$

where $s$ and $o$ indicate the simulated and observed variables, respectively, and $\bar{s}$ and $\bar{o}$ their temporal means. These statistics were chosen because they provide different useful and descriptive information:

(i) The Bias indicates the systematic error between the observation and the model solutions;

(ii) The RMSD represents the standard deviation between observed and modeled anomalies;

(iii) The NRMSE is used to understand the significant percentage of the standard deviation difference on the total water level or current amplitude (Sabatino et al. 2016);

(iv) The $R$ measures the concordance between observations and simulations with regard to the temporal variability, i.e., timing (Meccia et al. 2009);

(v) $P$ provides an indication whether the numerical solution fits to the magnitude of the observations as well as

(vi) $S S$, but this last takes a variance (energy) approach; finally,

(vii) $S k$ assesses a relative average error and is detailed discussed by Hetland and Campbell (2007) and Zhang et al. (2012). For a perfect model that exactly reproduces the observation, the model skill is of one. If the variance of the model error $(s-\bar{o})$ is equal to the variance of the data $(o-\bar{o})$, the skill is zero. It is possible to have a negative skill if the model error variance is larger than the data variance, i.e., the model strongly disagrees with the observations. 
Finally, for completeness, at the water-level stations the "root mean square error for tides" $\left(\Delta_{T}\right)$ was taken into account to assess the tidal component of the water level. This score is defined in Eq. 8:

$$
\Delta_{T}^{2}=\frac{1}{2}\left[A_{o}^{2}+A_{s}^{2}-2 A_{o} A_{s} \cos \left(\phi_{s}-\phi_{o}\right)\right]
$$

where $A_{o}$ and $A_{s}$ are the observed and simulated amplitude of one constituent, respectively, and $\phi_{o}$ and $\phi_{s}$ are the corresponding phases. This statistic utilizes the complex representation of the tidal constituents to compute a net difference blending amplitude and phase. The harmonic analysis of the simulations was made using Pytides (https://github.com/sam-cox/ pytides).

\section{Numerical model}

The primitive equations Coastal and Regional Ocean COmmunity model (CROCO, http:// www.croco-ocean.org) was chosen as the base for the development of our application. CROCO is the follow-on of ROMS_AGRIF (Regional Ocean Model System-Adaptive Mesh Refinement In Fortran, Debreu et al. 2012) and part of a French national initiative for regional modeling. The selection of CROCO was motivated by the fact that it is a free source code which widely accepted and applied (e.g., Combes and Matano 2019; Kresning et al. 2019), and that is suitable for the purpose of developing an operational system for the forecast of oceanic variables. In addition, CROCO includes the possibility of twoway interaction, that can be interesting and useful in future studies (e.g., Sakamoto et al. 2019). Since the storm surge is a barotropic process (e.g., Gill 1982; Pedlosky 1987; WMO 2011), CROCO model was applied on a barotropic 2D version, as it is usually done for the forecast/hindcast of the sea level and barotropic currents (WMO 2011). The 2D barotropic model is based on the depth-averaged horizontal momentum and continuity equations as follows:

$$
\begin{gathered}
\frac{\partial \boldsymbol{u}}{\partial t}+(\boldsymbol{u} \cdot \boldsymbol{\nabla}) \boldsymbol{u}+f \hat{z} \times \boldsymbol{u}=-g \boldsymbol{\nabla} \eta-\frac{1}{\rho_{0}} \nabla p_{a t}+\frac{1}{\rho_{0} H}\left(\boldsymbol{\tau}_{S}-\boldsymbol{\tau}_{B}\right) \\
\frac{\partial \eta}{\partial t}+\nabla \cdot(H \boldsymbol{u})=0
\end{gathered}
$$

where $\boldsymbol{u}$ represents the depth-averaged velocity; $t$ the time; $f$ the Coriolis parameter; $\hat{z}$ the versor normal to the surface; $g$ the acceleration due to gravity; $\eta$ the water level; $\rho_{0}$ the water density; $p_{a t}$ the surface atmospheric pressure; $H$ the total water depth, i.e., the addition of $\eta$ and the undisturbed water depth $(h) ; \tau_{S}$ and $\tau_{B}$ surface wind and bottom friction stress tensors, respectively.

It was necessary to modify the source code (originally $3 \mathrm{D}$ ) to run $2 \mathrm{D}$ simulations; tide and runoff subcodes were modified with this aim. Besides, a subroutine was added to force the model to take into account the effect of gradients in the atmospheric surface pressure $\left(\frac{1}{\rho_{0}} \nabla p_{a t}\right)$, that is not included in the original version of CROCO. This choice was based on the fact that the surface pressure gradient is significant all over the estuary, especially in the northern part of the domain (along the Uruguayan coast) due to the presence of a semipermanent low over Uruguay (Seluchi and Saulo 1996). The non-inclusion of this variable 
can produce uncertainties up to $0.10 \mathrm{~m}$ at the upper portion of the RdP (Dinápoli et al. 2020).

In the application discussed in this work, the RdP is reached through two nested domains of different scales. The Model $A$ is the lowest resolution/largest scale domain, and covers an area spanning from $69^{\circ} \mathrm{W}$ to $46^{\circ} \mathrm{W}$ and from $59^{\circ} \mathrm{S}$ to $26^{\circ} \mathrm{S}$ (Fig. 1 , subfigure). The horizontal resolution is of 7.50' and 5.25' in the zonal and meridional directions, respectively, which are equivalent to approximately $12 \mathrm{~km}$. Model A is used to provide boundary conditions to Model B (Fig. 1). This model is the higher resolution/lower scale domain for the RdP, spanning the region between $58.75^{\circ} \mathrm{W}$ and $52.50^{\circ} \mathrm{W}$, and $38.20^{\circ} \mathrm{S}$ and $32.60^{\circ} \mathrm{S}$. The horizontal resolution is of $2.5^{\prime}$ and $1.75^{\prime}$ in the zonal and meridional directions, respectively, or approximately $4 \mathrm{~km}$. Given that the wavelength of the tide is more than $300 \mathrm{~km}$ (Simionato et al. 2005a) and that the scale of the surge is near to $1000 \mathrm{~km}$ (Pugh 2004), a resolution of $4 \mathrm{~km}$ is enough to properly solve the processes of interest and provides a reasonable number of grid points describing them throughout the entire estuary, with at least 10 to 12 points even across its upper part (e.g., Simionato et al. 2004a; Luz Clara Tejedor et al. 2014; Moreira and Simionato 2019; Dinápoli et al. 2020). Incrementing the resolution, in order to provide detailed information about the circulation that may occur in small inlets along the estuary or within the ports, would be desirable. Nevertheless, this last will not be possible in the short term due to the lack of data of the bathymetric details in those regions of the RdP, except along the (narrow) navigation channels and in the vicinity and inside the main harbors. The chosen horizontal resolution is consistent with the 1/3 reduction criteria from father to child models (Simionato et al. 2006b; Santoro et al. 2011). Bathymetries for both models were built by combining ETOPO2v2 (Amante 2009) dataset with data provided by the SHN for depths shallower than $200 \mathrm{~m}$ that come from digitization of nautical charts (SHN 1986; 1992, 1993, 1999a, b).

Model $\mathrm{A}$ is forced along its lateral open boundaries by the astronomical tide composed by the 8 principal diurnal and semidiurnal constituents $\left(\mathrm{M}_{2}, \mathrm{~S}_{2}, \mathrm{~N}_{2}, \mathrm{~K}_{2}, \mathrm{~K}_{1}, \mathrm{O}_{1}, \mathrm{Q}_{1}\right.$ and $\left.\mathrm{P}_{1}\right)$ provided by the TPXO9 model (Egbert and Erofeeva 2002).

Surface and bottom stress tensors are computed through the quadratic parameterization, Eq. 11:

$$
\begin{gathered}
\tau_{\boldsymbol{S}}=c_{D}^{w} \rho_{A} w \boldsymbol{w} \\
\boldsymbol{\tau}_{\boldsymbol{B}}=c_{D} \rho_{0} u \boldsymbol{u}
\end{gathered}
$$

where is $c_{D}^{w}$ is the wind drag coefficient, $\rho_{A}$ is the air density, $w$ is the wind speed, $w$ is the wind vector, $c_{D}$ the quadratic bottom friction parameter, $\rho_{0}$ is the water density, $u$ is the current speed and $\boldsymbol{u}$ is the current vector. $c_{D}$ was set at 0.002 at every node of both $A$ and $B$ domains. $c_{D}^{w}$ was parameterized using the formula proposed by Bowden (1983), Eq. 12:

$$
c_{D}^{w}= \begin{cases}1.1 \times 10^{-3} & , \text { for } w<5 \mathrm{~m} \mathrm{~s}^{-1} \\ (1.1+0.06 w) \times 10^{-3} & , \text { for } w \geq 5 \mathrm{~m} \mathrm{~s}^{-1}\end{cases}
$$

Sea level pressure, surface air density and 10-m wind data are ERA5 and HRES from ECMWF.

For the continental discharge, daily observations (Borús et al. 2008) are used to set the Paraná and Uruguay rivers runoff (circles in Fig. 1), which are the main affluents accounting for more than $99 \%$ of the runoff to the estuary (Framinan et al. 1999).

The time steps of the father and child models is of 15 and $5 \mathrm{~s}$, respectively, consistent with the CFL criterion (Courant et al. 1928). Finally, the model solutions (water-level 
anomalies, or perturbations of the water level height with respect to the mean level, and barotropic current components) were saved every 1 hour time for the analysis.

In order to build a pre-operational system and to warranty its easy transference, the routines were automated using the object oriented programming (so-called OOP) techniques implemented in Python programming language. The numerical model was run on a cluster operating with Linux that has $24 \operatorname{Intel}(\mathrm{R})$ Xeon(R) CPU E5-2620 v3 @ 2.40GHz processors, with a cache memory of $15360 \mathrm{~KB}$ and 32 GB of RAM memory. Pre and post processing was made using Python, particularly with pandas (McKinney 2010), numpy (van der Walt et al. 2011) and xarray (Hoyer and Hamman 2017) libraries. Maps were made using cartopy (Met Office 2010-2015).

Summarizing, the pre-operational system works as follows:

1. Definition of the starting and ending times of the model run, which triggers the overall initiation of the system.

2. Downloading and storage of $10-\mathrm{m}$ wind, sea level pressure and surface air density from: (1) ERA5 when the model is run in hindcasting mode; (2) HRES when the model is run in forecasting mode.

3. Making Construction of the forcing file for Model A: interpolation of the atmospheric reanalysis and computation of the horizontal wind stress tensor. In the case of forecasting, hindcast and forecast fields are concatenated because the hindcast is utilized to force the model during the spin up. Addition of tidal forcing.

4. Model A is run.

5. Construction of the forcing file for Model B: as is indicated in 3 but correcting the atmospheric fields using the empirical calibration. Addition of runoff forcing.

6. Construction of the boundary forcing file interpolating the solutions of Model A into the boundaries of Model B.

7. Model B is run, and water level and barotropic current are saved every 1 hour of simulation.

8. Since numerical solutions are provided in a Arakawa-C grid (Arakawa and Lamb 1977), i.e., east-west/north-south current components shifted along the zonal/meridional direction respect the water level; the currents are re-gridded to the same points of the water level (Arakawa-A grid).

The integration of one calendar month takes one hour of computation; the first half corresponds to the integration of one month of spin-up (domain-averaged kinetic energy in steady-state) and the other half to the required simulation. In addition, the system was designed in a generic way to accommodate and integrate different regional and local models.

\section{Results}

\subsection{Atmospheric calibration}

In a previous work, a sensitivity analysis of the numerical model was carried out (Dinápoli et al. 2020). The analysis showed that the wind is by large the main source of uncertainties for forecasting/hindcasting the RdP. This way, a wind calibration was developed in order to improve this forcing and reduces the error in the solutions. Figure 2 displays the 
Fig. 2 Power spectral density (PSD) of the observed (solid blue line) and ERA5 reanalysis (solid red line) wind speed. Curves of $95 \%$ of significance with respect to red noise are shown in stroke lines, blue for observations and red for ERA5

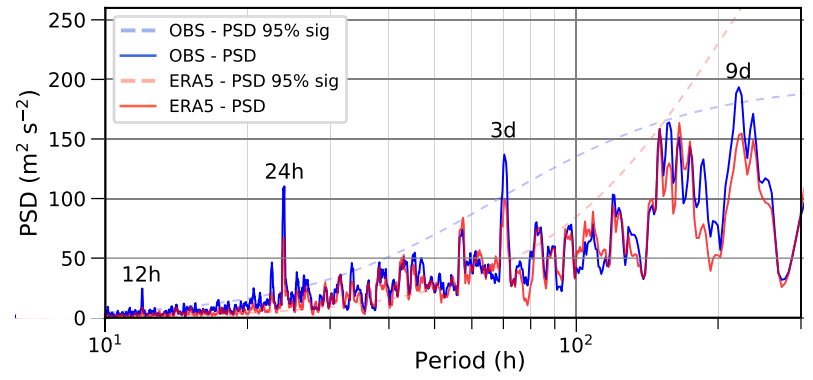

power spectral density (PSD) of the $10 \mathrm{~m}$ wind speed of the direct observations collected at OB (solid blue) compared to the ERA5 reanalysis data (solid red) for the period elapsed between November 2009 and December 2010. Figure 2 indicates that the reanalysis properly represent the wind variability at daily (12 and $24 \mathrm{~h}$ ) and synoptic time scales ( 3 and 9 days), which are the periods of interest. Nevertheless, a discrepancy in the amplitude is observed, mainly an underestimation of wind energy. Due to the ability of ERA5 to capture the temporal oscillations of the wind speed, the calibration was applied only to the amplitude through an empirical function.

Figure 3 presents the field of linear correlation $(R$, left panel) and regression $(P$, right panel) between the wind speed time series from the ERA5 reanalysis at OB and the same reanalysis at every other node of the model domain. The high scores found (linear regressions over 0.9 and correlations that exceed 0.8 over most of the estuary) suggests that the wind speed in this area is homogeneous enough to ensure that a calibration developed at OB can be applied, being particularly valid at the areas of largest socio-economic impacts of the surges.

For the empirical fitting, both observed and reanalyzed wind speed at $\mathrm{OB}$ were categorized into discrete intervals of $0.25 \mathrm{~m} \mathrm{~s}^{-1}$ by averaging. Then, an exponential-like function was fitted to the scatter plot of both datasets using the least square technique provided by the SciPy

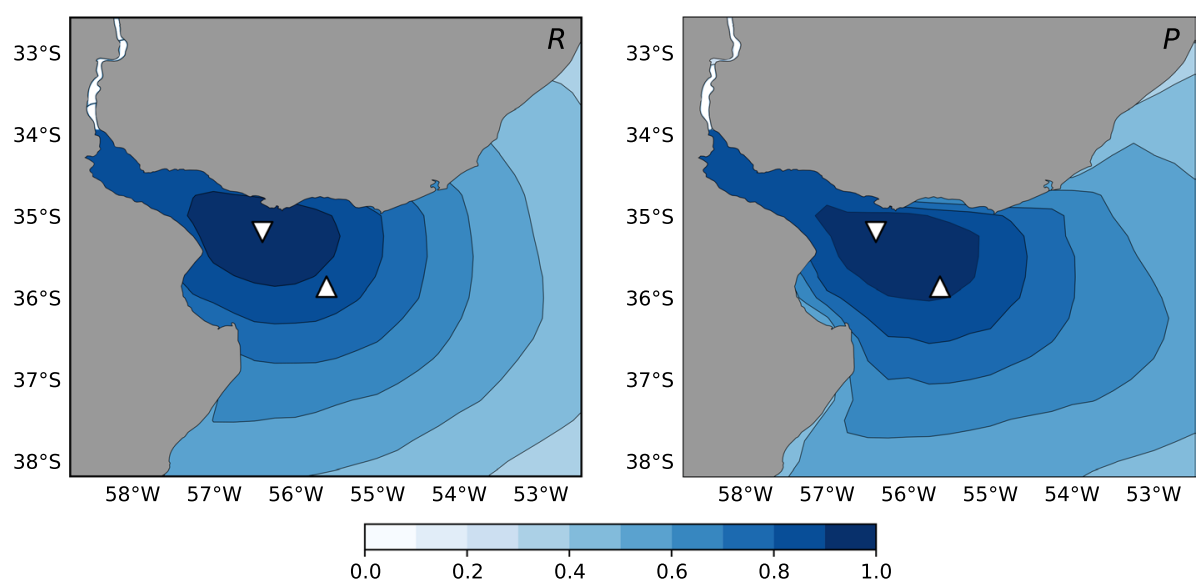

Fig. 3 Linear Pearson correlation $(R$, left panel) and linear regression $(P$, right panel) fields comparing the time series of wind speed at OB (white down-triangle) and the others nodes. Times series belong to ERA5 reanalysis. Oceanor buoy is marked with a white up-triangle. The stroke lines indicate the divisions of the estuary 
python library (Virtanen et al. 2019). The upper left panel of Fig. 4 shows the scatter plot of the wind speed $\left(w_{S}\right)$ from reanalysis versus observations (blue dots) and a minimum squares fitted curve (red line), whereas the upper right panel of Fig. 4 displays the histogram of the differences between the observations and the fit $(\varepsilon)$. The figure illustrates the good representation of the fitting function; discrepancies occur mainly for very large wind speeds (of more than $12 \mathrm{~m} \mathrm{~s}^{-1}$ ) that are not frequent in this region of the world (Simionato et al. 2005a; Dragani et al. 2010). The histogram shows the goodness of the fitting due to the Gaussian shape of $\varepsilon$ and the dominance of small values in the errors' distribution. The mathematical expression of the calibration function $(\Gamma)$ of the wind speed $\left(w_{S}\right)$ is in Eq. 13:

$$
\hat{w}_{S}=\Gamma\left(w_{S}\right) \cdot w_{S}=\left(0.17+e^{-\frac{0.29 w_{S}}{\left(w_{S}-1.77\right)^{2}}}\right) w_{S}
$$

A mathematical analysis shows that $\Gamma$ has an inflexion at $w_{c}=4.38 \mathrm{~m} \mathrm{~s}^{-1}$ : for lower values an attenuation is applied $(\Gamma<1)$ and, oppositely, an amplification is produced for larger $w_{S}$ $(\Gamma>1)$. The central panel of Fig. 4 presents a comparison between the observed (blue dots) and calibrated (red full line) $w_{S}$, where the good correspondence between both datasets is evident. In order to provide a visual validation, the fitting was applied to another data set. The lower panel of Fig. 4 presents a comparison of the observed (blue dots) and calibrated (red line) $w_{S}$ for the Oceanor station in the period from December 1998 to February 1999.
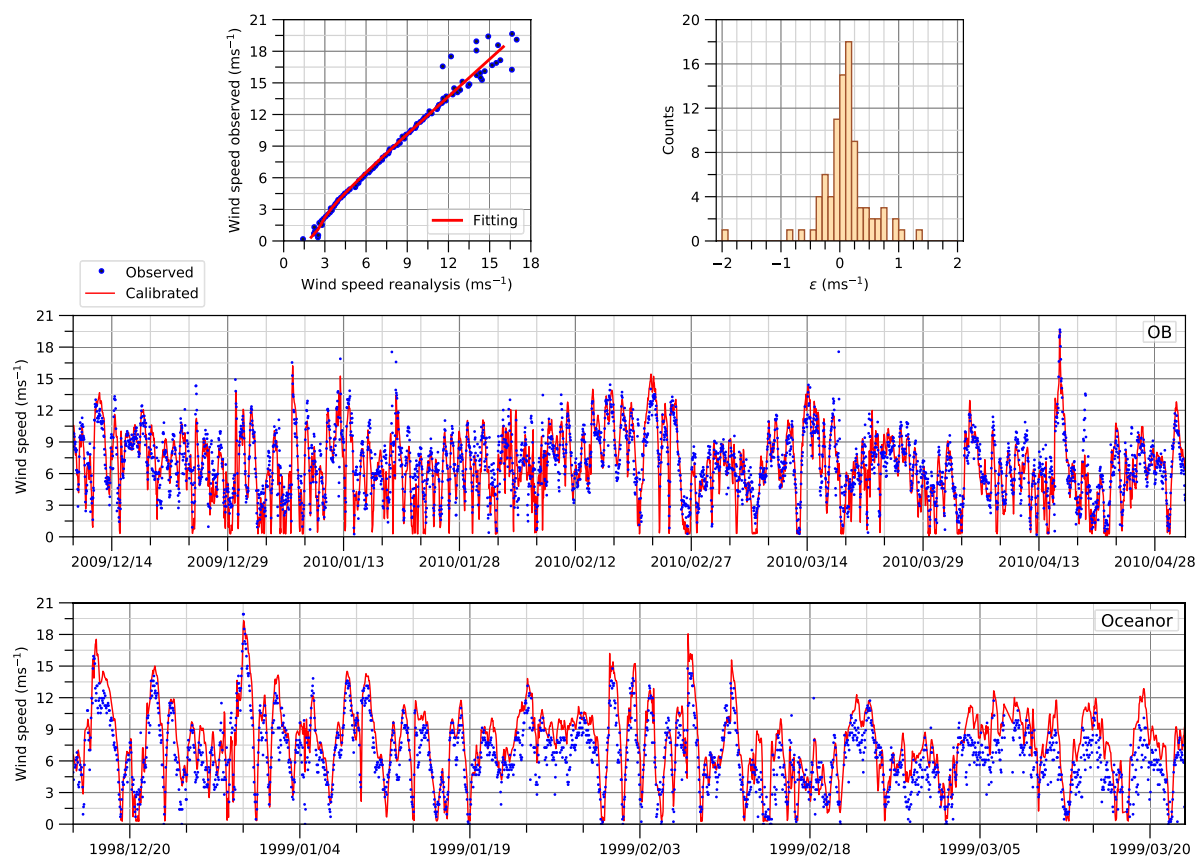

Fig. 4 Wind speed calibration and validation for the RdP. Upper left panel: scatter plot of the wind speed ERA5 reanalysis and direct observations, both categorized each $0.25 \mathrm{~m} \mathrm{~s}^{-1}$. Red lines represent the fitted curve. Upper right panel: histogram of differences $(\varepsilon)$ between observations and reanalysis values calibrated. Central panel: comparison of the calibrated wind speed (red line) and direct observed (blue dots) at OB station in 2010. Lower panel: comparison of the calibrated (red line) and observed (blue dots) wind speed at Oceanor station within 1998 and 1999 
This last plot confirms the good performance of the function for the calibration of ERA5 reanalysis.

Finally, Table 2 presents a statistical comparison of the raw reanalysis (ERA5) and the calibrated wind speed (ERA5-C) against direct observations and at OB and Oceanor stations. For OB the calibration decreases the bias, i.e., the systematic discrepancy of the mean wind speed; statistic scores what asses the time evolution (RMSE, NRMSE, R, Sk) remain constant, mainly keeping a NRMSE at $8 \%$, unaffecting the cycles of variation of the wind speed, as expected; those scores related to the amplitude ratio $(P, \mathrm{SS})$ increase, reaching values close to 1 and indicating a good correspondence. In the case of Oceanor (located outside the RdP estuary), similar results were obtained except for the bias; the calibration produces an increment of $30 \%$ suggesting an excessive intensification of the wind speed in the outer RdP. Due to the fact that our interest is mainly inside the estuary, the results for Oceanor are accepted.

Finally, for completeness, the same procedure was performed to the sea-level pressure with a categorization of $1 \mathrm{hPa}$. For sea-level pressure, a linear function was enough for the calibration; results indicate that ERA5 has an offset of $4 \mathrm{hPa}$ for this variable at the RdP (not shown).

\subsection{Hindcast evaluation for water level}

Figure 5 shows the observed (blue dots) and simulated (red line) water-level anomalies ( $\eta$, in meters) for the stations of Table 1; the period chosen for every subplot correspond to that when the strongest storm surges took place among the available observations. The figures illustrate the model ability to reproduce the observed levels along the RdP coasts and even out of the estuary (for instance, at Mar del Plata and La Paloma, Fig. 1). Table 3 summarizes the statistic scores computed. Since the water level is an anomaly, the bias does not apply in this case. Considering an "average score" for all the stations, it can be concluded that: (1) the dispersion $R M S D$ was of $0.22 \mathrm{~m}$, which corresponds to an error of up to $8 \%$; (2) the linear correlation $(R)$ and the regression $(P)$ are always above 0.80 inside of the estuary, indicating that the observed water level is well captured by the simulation in both timing and amplitude, respectively; (3) the symmetric slope $(S S)$ very close to 1 (over 0.91 for all the stations located inside the estuary), showing that the computed potential energy is in good agreement with the observed one; (4) finally, the skill score ( $S k$ ) is always over 0.90 inside the RdP, indicating more integrally the good performance of the numerical model in the reproduction of the water-level anomaly in the RdP estuary. Interestingly, the performance is acceptable even at the stations located outside the RdP, like La Paloma and Mar del Plata, the last one located at several hundred kilometers to the south.

Table 2 Statistical scores computed before and after the wind speed calibration

\begin{tabular}{lllllllll}
\hline & Reanalysis & $\begin{array}{l}\text { Bias } \\
\left(\mathrm{m} \mathrm{s}^{-1}\right)\end{array}$ & $\begin{array}{l}\text { RMSD } \\
\left(\mathrm{m} \mathrm{s}^{-1}\right)\end{array}$ & $\begin{array}{l}\text { NRMSE } \\
(\%)\end{array}$ & $P$ & $R$ & SS & Skill \\
\hline OB & ERA5 & -0.40 & 1.58 & 8 & 0.78 & 0.86 & 0.91 & 0.92 \\
& ERA5-C & 0.07 & 1.84 & 9 & 0.99 & 0.85 & 1.16 & 0.92 \\
\multirow{3}{*}{ Oceanor } & ERA5 & 0.41 & 1.63 & 8 & 0.76 & 0.87 & 0.88 & 0.92 \\
& ERA5-C & 1.13 & 1.83 & 11 & 0.95 & 0.86 & 1.10 & 0.92 \\
\hline
\end{tabular}


Fig. 5 Comparisons of water level ( $\eta$, in meters) from numerical model (red line) and tidal gauges (blue dots) at several stations
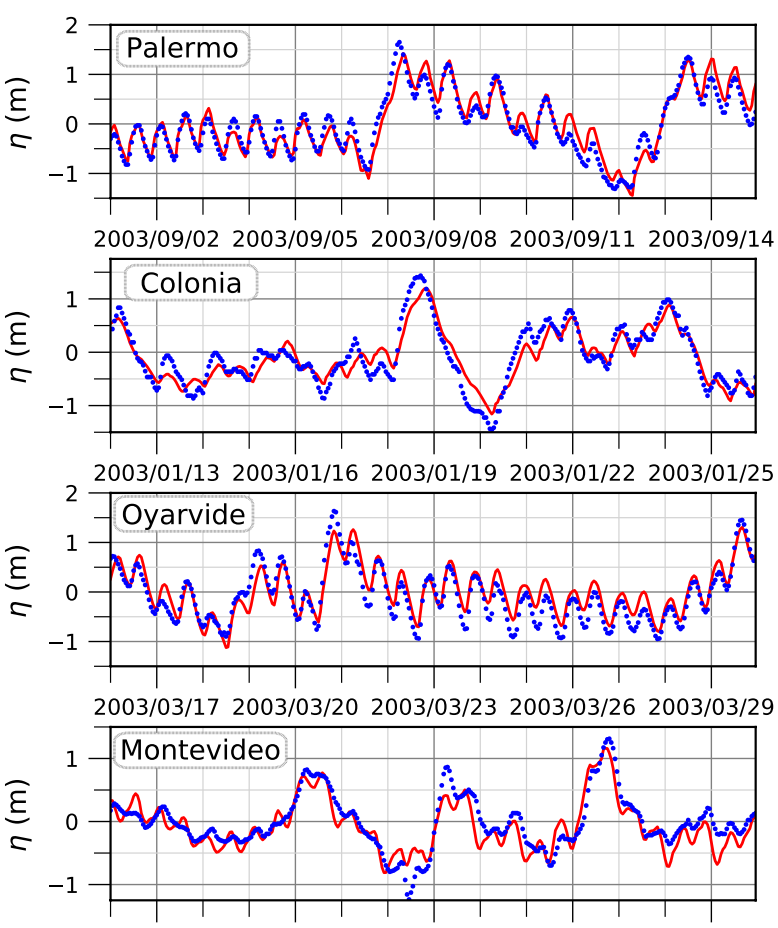

2002/12/14 2002/12/17 2002/12/20 2002/12/23 2002/12/26

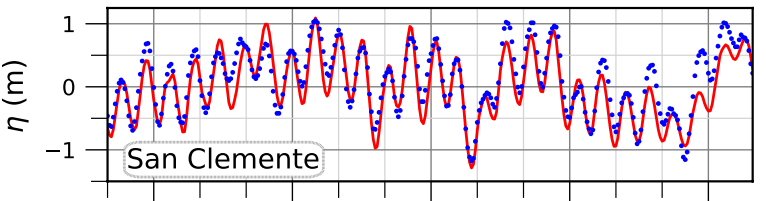

1998/12/28 1998/12/31 1999/01/03 1999/01/06 1999/01/09
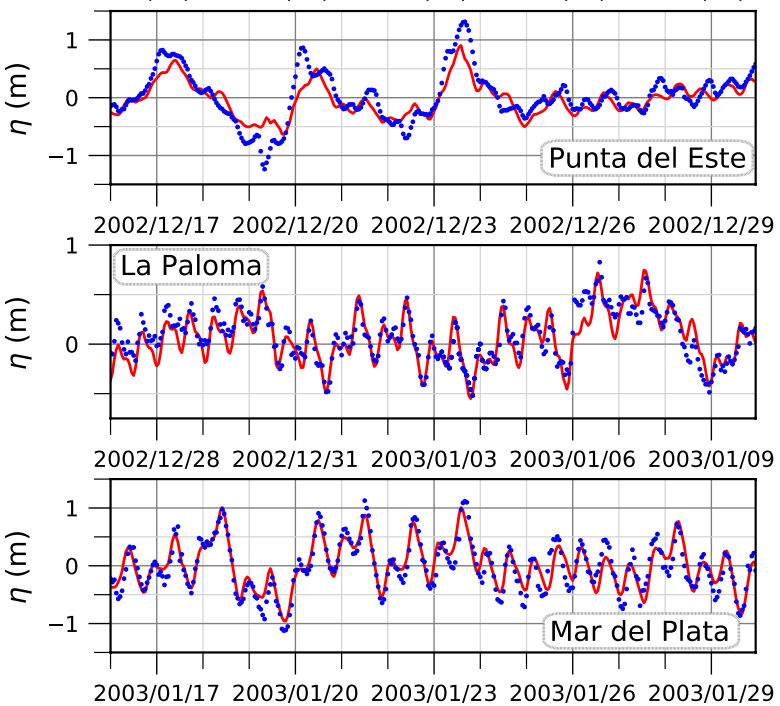
Table 3 Statistical scores computed for the water level hindcast at several stations

\begin{tabular}{lllllll}
\hline Station & $\begin{array}{l}\text { RMSD } \\
(\mathrm{m})\end{array}$ & $\begin{array}{l}\text { NRMSE } \\
(\%)\end{array}$ & $P$ & $R$ & $S S$ & $S k$ \\
\hline Palermo & 0.25 & 6 & 0.95 & 0.89 & 0.94 & 0.94 \\
Colonia & 0.28 & 8 & 0.88 & 0.82 & 0.94 & 0.90 \\
Oyarvide & 0.26 & 8 & 0.93 & 0.84 & 0.91 & 0.91 \\
Montevideo & 0.20 & 8 & 0.86 & 0.86 & 1.00 & 0.92 \\
San Clemente & 0.20 & 7 & 0.93 & 0.90 & 0.98 & 0.93 \\
Punta del Este & 0.23 & 9 & 0.99 & 0.77 & 0.78 & 0.86 \\
La Paloma & 0.15 & 7 & 0.80 & 0.85 & 1.07 & 0.92 \\
Mar del Plata & 0.16 & 6 & 1.03 & 0.92 & 0.89 & 0.96 \\
\hline
\end{tabular}

To analyze in particular the capability of the numerical model to simulate the waterlevel oscillations due to tides, Fig. 6 presents a comparison between the observed (blue bars) and modeled (red bars) tidal amplitudes (left panel) and phases (right panel) of the eight dominant tidal constituents at the diverse coastal locations of the RdP (Fig. 1 and Table 1); to complement the analysis, comparisons for Mar del Plata, Pinamar and La Paloma stations (located outside the estuary) are also presented. Figure 6 shows that the model can properly reproduce the energy (amplitude) and timing (phase) of every tidal constituents even for those ones outside of RdP. In order to provide a quantitative comparison. Table 4 shows the root mean square error $\left(\Delta_{T}\right.$ in meters) for the every tidal constituent at every station. The values indicate that the differences are on average to $0.03 \mathrm{~m}$. The relatively large errors of $S_{2}$ at Mar del Plata and San Clemente can be related to errors in the bathymetry. Regarding $\mathrm{K}_{1}$, its errors are relatively large for every station, hence, it can be related to the propagation of this constituent in the Model A. Nonetheless, in the domain B, $\mathrm{K}_{1}$ explains up to $9 \%$ of the total tidal variance. In summary, Fig. 6 and Table 4 illustrate that the tide and, particularly, the most important tidal constituent $\mathrm{M}_{2}$ (D'Onofrio et al. 2008) are properly represented at all the stations by the model.

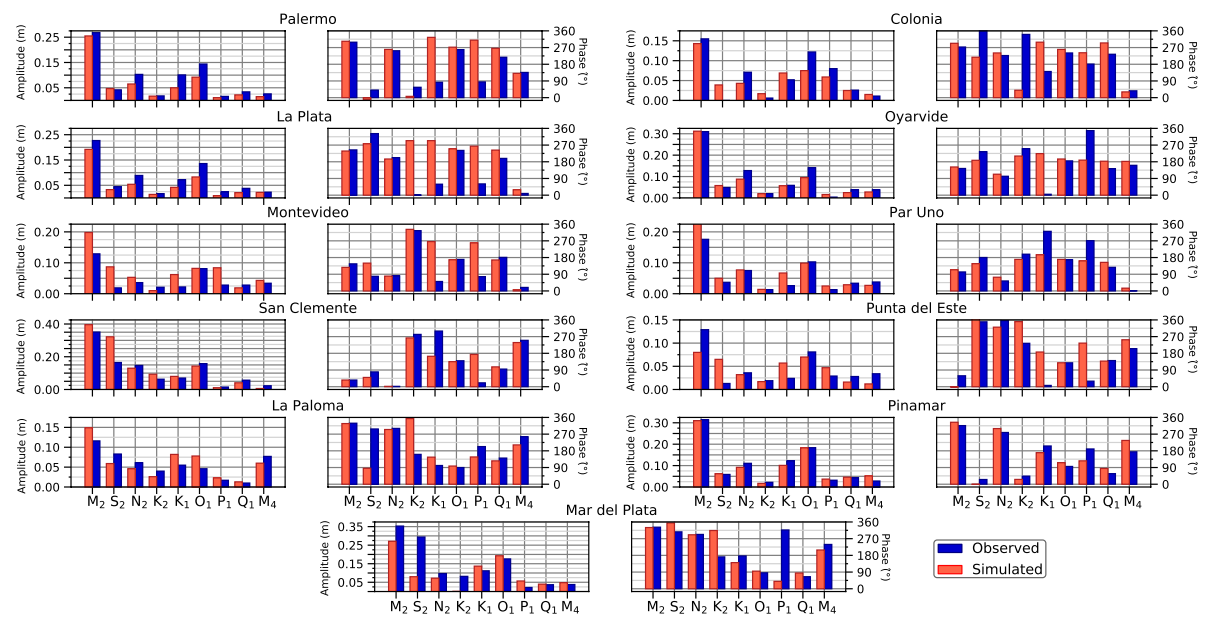

Fig. 6 Tidal amplitude and phase comparison for the dominant constituents in the RdP, observed in blue and computed in red 
Table 4 Root mean square $\left(\Delta_{T}\right.$, in $\left.\mathrm{m}\right)$ for the main tidal constituents at several locations

\begin{tabular}{llllllllll}
\hline Station & $\mathrm{M}_{2}$ & $\mathrm{~S}_{2}$ & $\mathrm{~N}_{2}$ & $\mathrm{~K}_{2}$ & $\mathrm{~K}_{1}$ & $\mathrm{O}_{1}$ & $\mathrm{P}_{1}$ & $\mathrm{Q}_{1}$ & $\mathrm{M}_{4}$ \\
\hline Palermo & 0.02 & 0.03 & 0.03 & 0.01 & 0.09 & 0.04 & 0.02 & 0.02 & 0.01 \\
Colonia & 0.04 & 0.03 & 0.02 & 0.01 & 0.08 & 0.04 & 0.05 & 0.02 & 0.00 \\
La Plata & 0.03 & 0.03 & 0.03 & 0.01 & 0.07 & 0.04 & 0.02 & 0.02 & 0.01 \\
Oyarvide & 0.03 & 0.03 & 0.03 & 0.01 & 0.08 & 0.04 & 0.01 & 0.02 & 0.01 \\
Montevideo & 0.06 & 0.06 & 0.01 & 0.01 & 0.06 & 0.00 & 0.08 & 0.01 & 0.01 \\
Par Uno & 0.06 & 0.02 & 0.02 & 0.00 & 0.06 & 0.00 & 0.02 & 0.01 & 0.01 \\
San Clemente & 0.03 & 0.14 & 0.01 & 0.03 & 0.10 & 0.01 & 0.02 & 0.01 & 0.01 \\
Punta del Este & 0.08 & 0.04 & 0.01 & 0.02 & 0.06 & 0.01 & 0.05 & 0.01 & 0.02 \\
La Paloma & 0.02 & 0.10 & 0.01 & 0.05 & 0.04 & 0.02 & 0.01 & 0.00 & 0.04 \\
Pinamar & 0.07 & 0.02 & 0.03 & 0.01 & 0.05 & 0.05 & 0.03 & 0.02 & 0.03 \\
Mar del Plata & 0.06 & 0.18 & 0.02 & 0.06 & 0.06 & 0.02 & 0.04 & 0.01 & 0.02 \\
\hline
\end{tabular}

Figure 7 presents the scatter plot (black dots) between the simulated and observed $\mathrm{M}_{2}$ for amplitude (left panel) and the phase (right panel); the red line indicates the ideal fit. Results show that the model can properly capture both the amplitude and phase of the tidal constituent, with a better accuracy in the phase (i.e., the timing of the tide), particularly for the stations located inside of the estuary. The largest error occurs at La Paloma, where tides are of very small amplitude, and the time series available for comparison are relatively short.

As a complementary assessment of the performance of the simulations, the $\mathbf{M}_{4}$ nonlinear tidal constituent was validated because it can be considered as a measure of the model capability to reproduce the tidal propagation in shallow areas (Pugh 2004). Figure 8 presents the scatter plot (black dots) between the simulated and observed $\mathrm{M}_{4}$ for amplitude (left panel) and the phase (right panel); the red line indicates the relation 1:1 (ideal fit). On average, the root mean square error (Table 4) computed for every station was up to $0.01 \mathrm{~m}$, which corresponds, approximately, to $25 \%$ for all stations. Results
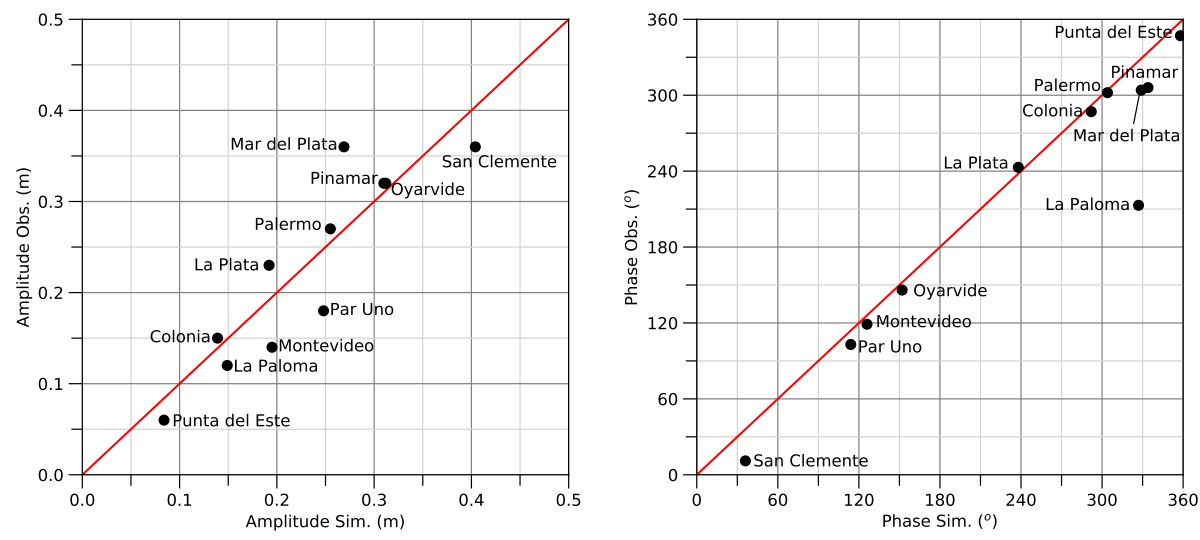

Fig. 7 Scatter plots of simulated versus observed amplitudes (left panel) and phases (right panel) for $\mathrm{M}_{2}$ tidal constituent. The full red line indicates the perfect fit 

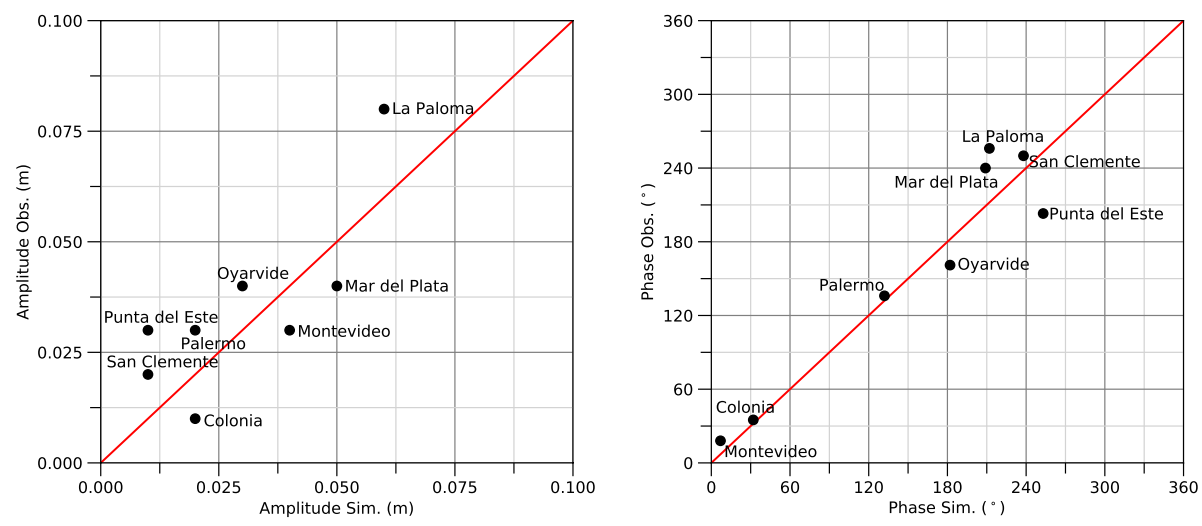

Fig. 8 Scatter plots of simulated versus observed amplitudes (left panel) and phases (right panel) for $\mathbf{M}_{4}$ tidal constituent. The full red line indicates the perfect fit

indicate that the model reasonably reproduces $\mathrm{M}_{4}$, especially in timing (phase), even errors in the amplitude are comparatively larger than those for $\mathbf{M}_{2}$.

\subsection{Hindcast evaluation for currents}

Figure 9 shows a comparison between the observed (blue dots) and computed (red line) zonal ( $U$, left panel) and meridional ( $V$, right panel) depth-averaged horizontal current components at the stations of Fig. 1 and Table 1 . The model solutions have a satisfactory performance in the representation of both variables. The fact that the model provides good results even at stations located at the exterior RdP (PON, ARG and even Oceanor, out of the estuary) confirms the adequacy of the choice of a barotropic model to reproduce the surge and the tide in the RdP, even in those areas where baroclinic processes become relatively more important. In fact, Simionato et al. (2007) demonstrated from direct current observations at the salt wedge of the RdP that the gravitational circulation is very small compared to the wind forced signal that dominates in this estuary, and not detectable even in one year of data.

Table 5 presents the statistical scores computed for every station for $U$ and $V$. In general, a small difference in the mean current (bias, of the order of a few centimeters per second) and a mean dispersion (RMSD) about $0.10 \mathrm{~m} \mathrm{~s}^{-1}$ are observed. Together, the bias and dispersion represents a porcentual error of about $13 \%$. Regarding the other scores, their closeness to 1 indicates that: (1) the evolution of both the amplitude $(P)$ and timing $(R)$ is well captured by the model; (2) the kinetic energy ( $S S$ ) is, on average, of about $78 \%$, suggesting that the mean current is slightly underestimated; and (3) the model is capable of representing the dynamic of the currents with skill scores $(S k)$ over to 0.80 for all the stations inside the estuary. The good score obtained for Oceanor indicates that the numerical model properly reproduces the barotropic component of the current outside of the RdP, which encourages its application for practical purposes at the coastal stations located at the adjacent continental Shelf.

To complement the tidal validation, tidal ellipses were computed using Utide python library. Figure 10 presents a comparison between the simulated (red) and observed (blue) tidal ellipses for the $\mathrm{M}_{2}$ tidal constituent, which accounts for most of the tidal energy in 

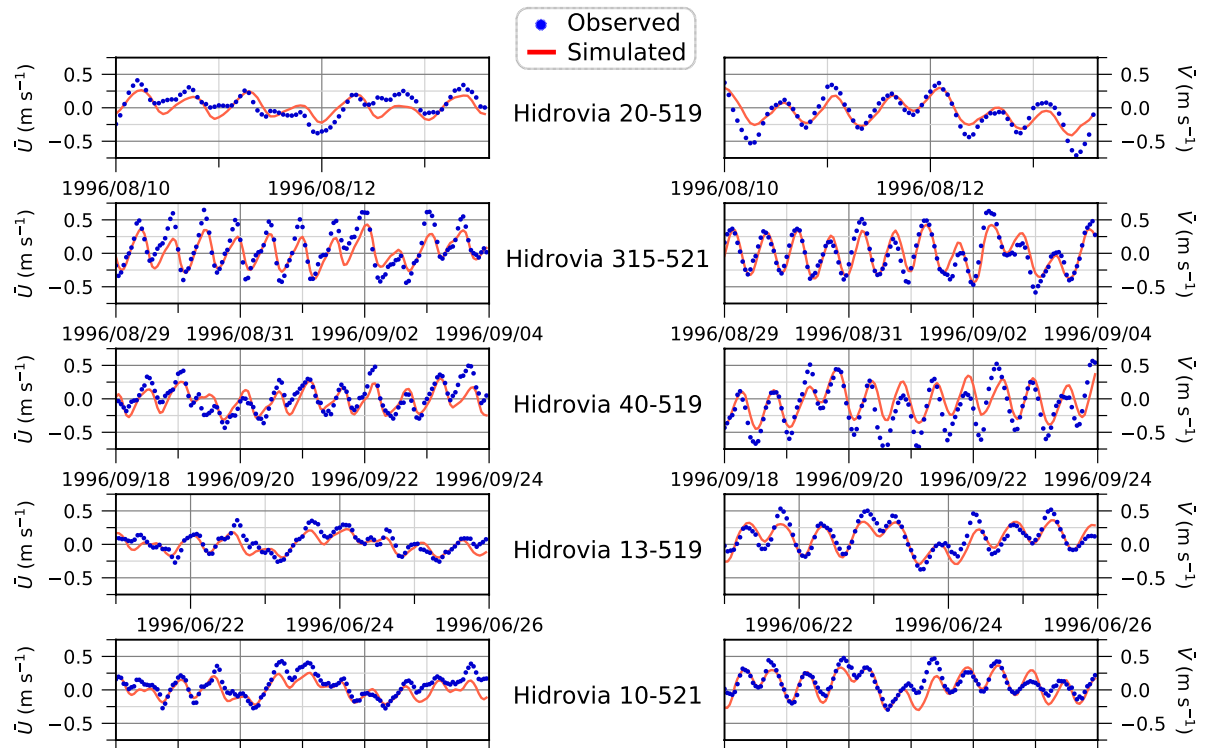

Hidrovia 13-519

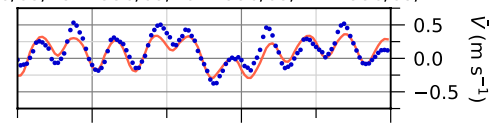

1996/06/21 1996/06/23 1996/06/25 1996/06/27

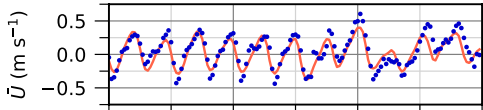

Hidrovia 30-519

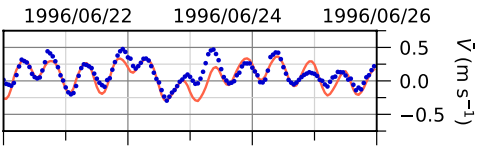

$1996 / 06 / 21 \quad 1996 / 06 / 23 \quad 1996 / 06 / 25 \quad 1996 / 06 / 27$

$\begin{array}{llll}1996 / 08 / 29 & 1996 / 08 / 31 & 1996 / 09 / 02 & 1996 / 09 / 04\end{array}$

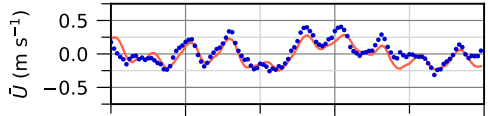

Hidrovia 12-518

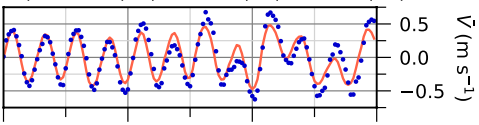

$\begin{array}{llll}1996 / 08 / 29 & 1996 / 08 / 31 & 1996 / 09 / 02 & 1996 / 09 / 04\end{array}$

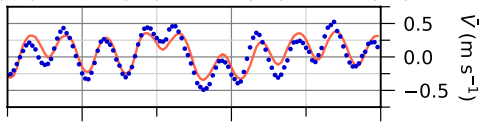

1996/06/22 1996/06/24 1996/06/26

$1996 / 06 / 22 \quad 1996 / 06 / 24 \quad 1996 / 06 / 26$

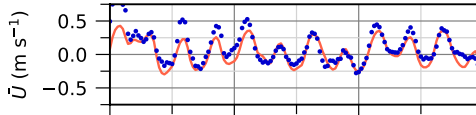

Hidrovia 21-521

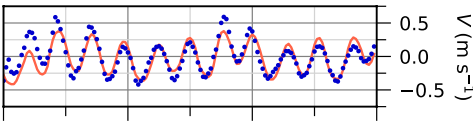

$\begin{array}{llll}1996 / 08 / 06 & 1996 / 08 / 08 & 1996 / 08 / 10 & 1996 / 08 / 12\end{array}$

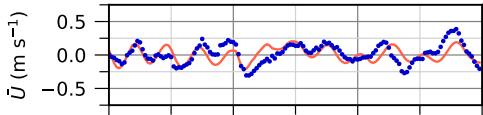

1996/08/06 1996/08/08 1996/08/10 1996/08/12

Oceanor

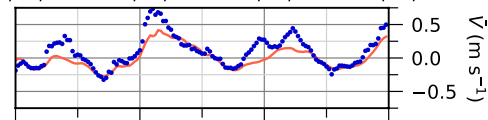

1999/02/05 1999/02/07 1999/02/09 1999/02/11

$\begin{array}{lllll}1999 / 02 / 05 & 1999 / 02 / 07 & 1999 / 02 / 09 & 1999 / 02 / 11\end{array}$
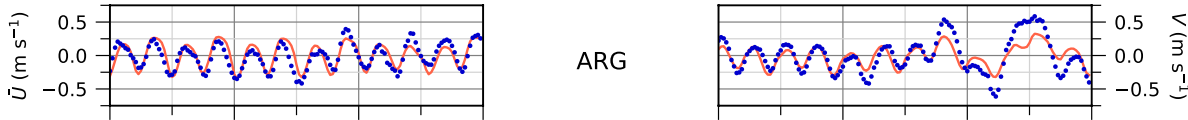

2003/01/01 2003/01/03 2003/01/05 2003/01/07

ARG

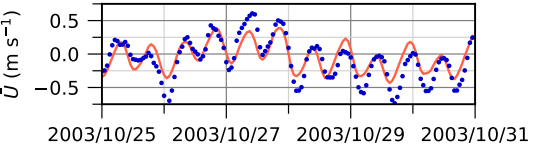

PON

2003/01/01 2003/01/03 2003/01/05 2003/01/07

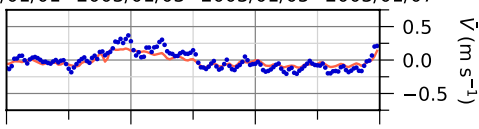

2003/10/25 2003/10/27 2003/10/29 2003/10/31

Fig. 9 Comparisons of zonal ( $U$, left panel) and meridional ( $V$, right panel) transport (in meter per seconds) from numerical model (red line) and current meters stations (blue dots)

the region (D'Onofrio et al. 1999). At all the analyzed stations, a good estimation of the phase, orientation (direction of the ellipse major axis) and amplitude by the simulation is observed at both the RdP and the adjacent shelf. 
Table 5 Statistical scores computed for the transport hindcast at several stations

\begin{tabular}{|c|c|c|c|c|c|c|c|c|}
\hline Station & Comp. & $\begin{array}{l}\text { Bias } \\
\left(\mathrm{m} \mathrm{s}^{-1}\right)\end{array}$ & $\begin{array}{l}R M S D \\
\left(\mathrm{~m} \mathrm{~s}^{-1}\right)\end{array}$ & $\begin{array}{l}\text { NRMSE } \\
(\%)\end{array}$ & $P$ & $R$ & $S S$ & Skill \\
\hline \multirow[t]{2}{*}{ H. $315-521$} & $\mathrm{U}$ & -0.05 & 0.15 & 14 & 1.33 & 0.89 & 0.67 & 0.89 \\
\hline & $\mathrm{V}$ & -0.00 & 0.13 & 10 & 1.02 & 0.89 & 0.87 & 0.94 \\
\hline \multirow[t]{2}{*}{ H. $40-519$} & $\mathrm{U}$ & -0.04 & 0.13 & 15 & 1.05 & 0.77 & 0.74 & 0.84 \\
\hline & $\mathrm{V}$ & 0.09 & 0.19 & 16 & 1.16 & 0.81 & 0.70 & 0.84 \\
\hline \multirow[t]{2}{*}{ H. 13-519 } & $\mathrm{U}$ & -0.03 & 0.08 & 14 & 1.05 & 0.82 & 0.78 & 0.87 \\
\hline & $\mathrm{V}$ & -0.02 & 0.10 & 12 & 0.99 & 0.87 & 0.88 & 0.92 \\
\hline \multirow[t]{2}{*}{ H. $10-521$} & $\mathrm{U}$ & -0.07 & 0.09 & 16 & 1.15 & 0.86 & 0.74 & 0.85 \\
\hline & $\mathrm{V}$ & -0.04 & 0.10 & 15 & 0.76 & 0.83 & 1.09 & 0.89 \\
\hline \multirow[t]{2}{*}{ H. $30-519$} & $\mathrm{U}$ & -0.03 & 0.11 & 11 & 1.06 & 0.88 & 0.83 & 0.92 \\
\hline & $\mathrm{V}$ & 0.01 & 0.13 & 10 & 1.14 & 0.92 & 0.81 & 0.95 \\
\hline \multirow[t]{2}{*}{ H. $12-518$} & $\mathrm{U}$ & -0.03 & 0.09 & 13 & 0.99 & 0.86 & 0.87 & 0.91 \\
\hline & $\mathrm{V}$ & 0.03 & 0.11 & 11 & 1.07 & 0.90 & 0.84 & 0.93 \\
\hline \multirow[t]{2}{*}{ H. $21-521$} & $\mathrm{U}$ & -0.07 & 0.12 & 11 & 1.11 & 0.88 & 0.79 & 0.89 \\
\hline & $\mathrm{V}$ & -0.02 & 0.12 & 12 & 0.93 & 0.87 & 0.93 & 0.93 \\
\hline \multirow[t]{2}{*}{ ARG } & $\mathrm{U}$ & 0.02 & 0.10 & 13 & 0.86 & 0.84 & 0.97 & 0.91 \\
\hline & V & -0.01 & 0.15 & 12 & 1.47 & 0.87 & 0.59 & 0.86 \\
\hline \multirow[t]{2}{*}{ PON } & $\mathrm{U}$ & 0.04 & 0.16 & 12 & 1.29 & 0.87 & 0.68 & 0.89 \\
\hline & $\mathrm{V}$ & -0.01 & 0.07 & 12 & 1.53 & 0.89 & 0.59 & 0.88 \\
\hline \multirow[t]{2}{*}{ Oceanor } & $\mathrm{U}$ & -0.01 & 0.12 & 17 & 0.76 & 0.57 & 0.75 & 0.74 \\
\hline & $\mathrm{V}$ & -0.09 & 0.11 & 14 & 1.23 & 0.89 & 0.72 & 0.87 \\
\hline
\end{tabular}

\section{Model evaluation for extreme storm surges}

So far, the numerical model in hindcast mode has demonstrated a satisfactory capability to reproduce the water-level and the depth-averaged horizontal currents for the periods when observations are available. This section presents the particular evaluation of both hindcast and forecast configurations during extreme storm surges. The assessment is focused on the five most recent positive and negative extreme events that affected Palermo station during the last two decades (i.e., 2000-2020). Positive extreme storm surge was determined following the criteria proposed by D'Onofrio et al. (2008) for Palermo station; that is, periods when: (1) residual levels (difference between the total water level and the tidal harmonic prediction) remain above $0.30 \mathrm{~m}$, and (2) the highest residual value is equal to or greater than $1.60 \mathrm{~m}$. The last value is chosen because, when combined with the mean water level during rising semidiurnal tide, it leads to warning levels at the station. Similarly, the criteria for negative extreme storm surge periods are: (1) residual levels that remain lower than $-0.30 \mathrm{~m}$, and (2) a lowest residual value is equal to or less than $-1.20 \mathrm{~m}$. The value $-1.20 \mathrm{~m}$ was chosen because a height close to the mean water level during a falling semidiurnal tide produces heights lower than $-0.40 \mathrm{~m}$ during at least $6 \mathrm{~h}$. The value of $\pm 0.30 \mathrm{~m}$ as a threshold value for positive and negative storm surges is because when the meteorological surge is negligible, the difference between the observed level and the predicted tide is within $\pm 0.10 \mathrm{~m}$. Hence, 

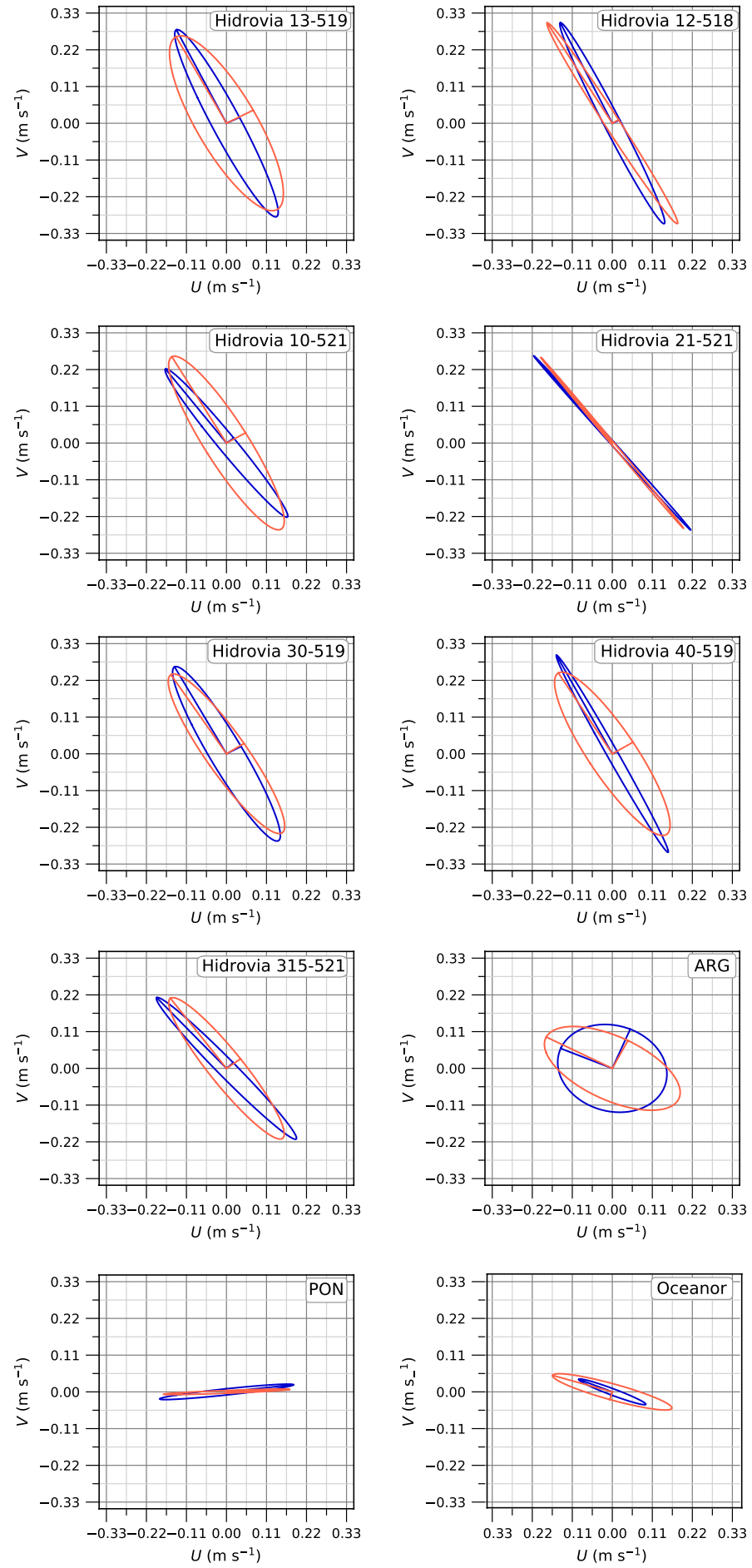

Fig. 10 Comparison of measured (blue) and computed (red) $\mathrm{M}_{2}$ tidal ellipses 


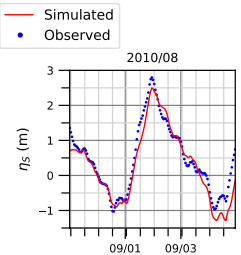

2006/07
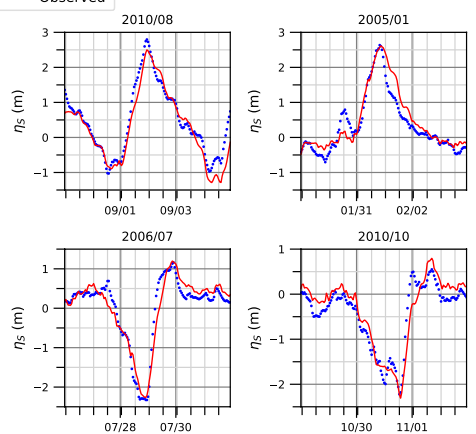

2010/10

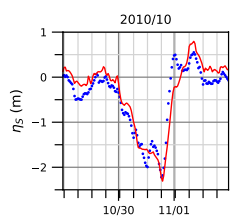

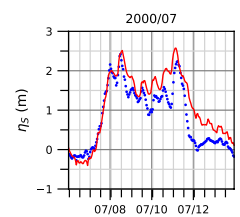

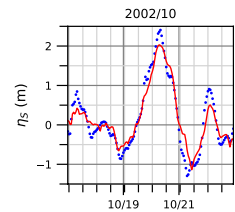

2009/07
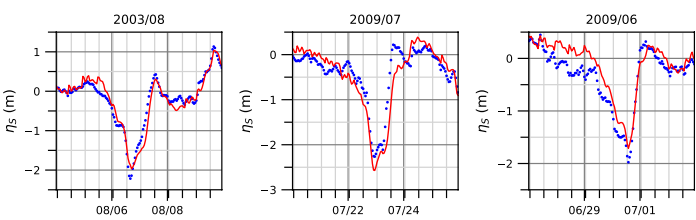

Fig. 11 Comparisons of residual levels ( $\eta_{S}$, in meters) from hindcast model (red line) and gauges (blue dots) at Palermo stations for historical extreme positive (upper panel) and negative (lower panel) storm surge

Table 6 Statistical scores computed for the hindcast of residual levels $\left(\eta_{S}\right)$ at Palermo stations

\begin{tabular}{llcllll}
\hline Event & $\begin{array}{l}\text { RMSD } \\
(\mathrm{m})\end{array}$ & $\begin{array}{l}\text { NRMSE } \\
(\%)\end{array}$ & $P$ & $R$ & $S S$ & $S k$ \\
\hline $2010 / 09$ & 0.28 & 8 & 0.91 & 0.96 & 1.05 & 0.97 \\
$2005 / 01$ & 0.28 & 9 & 0.89 & 0.95 & 1.07 & 0.97 \\
$2000 / 05$ & 0.18 & 10 & 0.92 & 0.98 & 1.06 & 0.97 \\
$2000 / 10$ & 0.18 & 6 & 1.00 & 0.97 & 0.97 & 0.98 \\
$2002 / 10$ & 0.25 & 7 & 1.13 & 0.96 & 0.85 & 0.97 \\
$2006 / 07$ & 0.26 & 7 & 0.97 & 0.95 & 0.98 & 0.98 \\
$2010 / 10$ & 0.27 & 10 & 0.86 & 0.94 & 1.10 & 0.96 \\
$2003 / 08$ & 0.18 & 5 & 0.93 & 0.96 & 1.03 & 0.98 \\
$2009 / 07$ & 0.30 & 12 & 0.75 & 0.93 & 1.24 & 0.95 \\
$2009 / 06$ & 0.19 & 11 & 1.01 & 0.94 & 0.94 & 0.94 \\
\hline
\end{tabular}

The middle line separates the positive events from the negative ones

to ensure that the chosen residuals corresponded to positive or negative storm surges, the threshold value adopted is three times the above difference (D'Onofrio et al. 2008).

Figure 11 shows the residual levels $\left(\eta_{S}\right)$ from the observations (blue dots) and the hindcast model solutions (solid red lines) for the five most extreme positive (upper panel) and negative (lower panel) storm surges over the last 20 years. Note that events are sorted by descending order from left to right. Table 6 presents the statistical scores computed for the events; the time periods for the calculation correspond to the periods displayed in Fig. 11. In general, the model performance is satisfactory. On average, $R M S D$ is lower than $0.25 \mathrm{~m}$ (about 9\%), similar to the results presented above for normal conditions. The linear regression $(P)$ and the symmetric slope $(S S)$ are 0.93 and 1.03, respectively, suggesting that the surge amplitude, and therefore the potential energy, is properly represented by the model. Linear correlations $(R)$ are above 0.95 , indicating a proper timing in the simulations. The previous scores are summarized by the averaged skill score $(S k)$ of 0.96 , which allows us to conclude that the hindcast model is useful also for very extreme events.

Figure 12 presents the residual levels $\left(\eta_{S}\right)$ forecasted for the same ten extreme events. Once more, observations are represented by blue dots and the model solutions by solid 

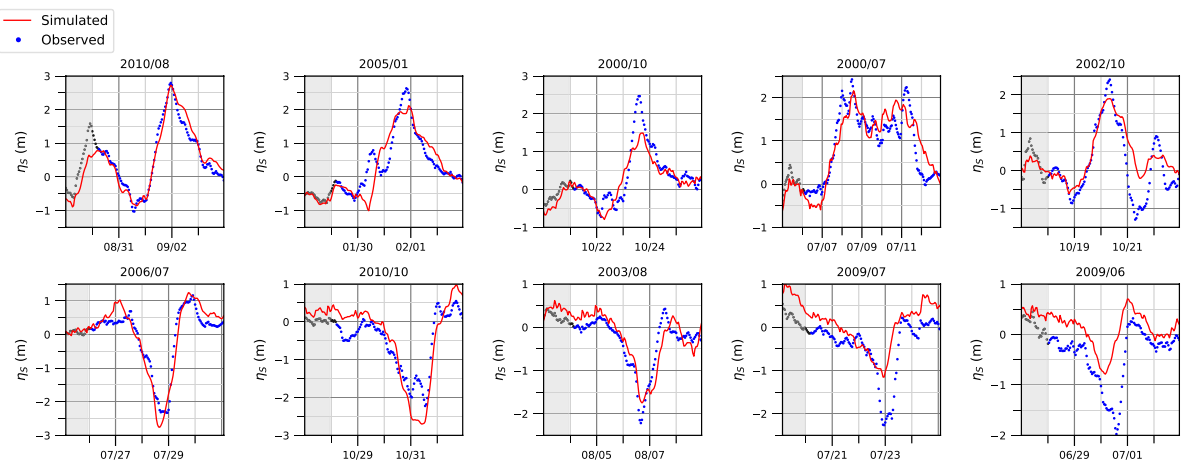

Fig. 12 Comparisons of residual levels ( $\eta_{S}$, in meters) from forecast model (red line) and gauges (blue dots) at Palermo stations for extreme positive (upper panel) and negative (lower panel) storm surges. Gray shaded areas indicate the time previous to the forecasting

red lines; the gray shades indicate part of the spin up period, when the model was forced with atmospheric reanalyses. In general, the model is able to reproduce the development of the storm surges. Table 7 presents the statistical scores for every event calculated over the periods not shaded in Fig. 12. Taking into account the nature of the forecast forcing, the NRMSD, on average $15 \%$, are consistent with the results reported with the hindcast. On average, the linear correlation $(R)$ and regression $(P)$ are both equal to 0.89 and 0.96 , respectively, suggesting that surge timings and amplitudes are well represented. Regarding the averaged simulated potential energy (symmetric slope, $S S$ ) equal to 0.97 indicates that is in good agreement with the observed one. Finally, the skill score $(S k)$ averaged on 0.89 supports the model application as a forecasting tool. Nonetheless, for some events (for instance, 2000/10 and 2009/07), the forecast error was close to $1.0 \mathrm{~m}$, i.e., a difference about $40 \%$ respect the surge peak. Since hindcasting results were optimal, it can be concluded that the limitation of the forecasting is due to limitations in the forcing fields instead of the oceanic numerical model. In this sense, the consideration of forcing uncertainties becomes relevant for a proper forecast, for instance, including an ensemble of fields that represents the atmospheric errors.

Table 7 Statistical scores computed for the forecast of residual levels $\left(\eta_{S}\right)$ at Palermo stations

\begin{tabular}{lllllll}
\hline Event & $\begin{array}{l}\text { RMSD } \\
(\mathrm{m})\end{array}$ & $\begin{array}{l}\text { NRMSE } \\
(\%)\end{array}$ & $P$ & $R$ & $S S$ & $S k$ \\
\hline $2010 / 09$ & 0.24 & 6 & 0.94 & 0.97 & 1.03 & 0.98 \\
$2005 / 01$ & 0.46 & 14 & 0.82 & 0.86 & 1.06 & 0.93 \\
$2000 / 10$ & 0.34 & 11 & 1.21 & 0.90 & 0.74 & 0.92 \\
$2000 / 07$ & 0.39 & 14 & 0.87 & 0.88 & 1.02 & 0.94 \\
$2002 / 10$ & 0.47 & 14 & 1.13 & 0.86 & 0.77 & 0.89 \\
$2006 / 07$ & 0.33 & 10 & 0.81 & 0.96 & 1.18 & 0.97 \\
$2010 / 10$ & 0.48 & 17 & 0.64 & 0.93 & 1.46 & 0.93 \\
$2003 / 08$ & 0.29 & 11 & 0.86 & 0.88 & 1.03 & 0.94 \\
$2009 / 07$ & 0.42 & 23 & 1.02 & 0.76 & 0.75 & 0.75 \\
$2009 / 06$ & 0.31 & 26 & 1.32 & 0.85 & 0.64 & 0.67 \\
\hline
\end{tabular}

The middle line separates the positive events from the negative ones 


\section{Comparison with recent applications for other coastal regions of the world}

In this section, the results of our work are compared to international research on the topic. With that aim, Table 8 presents some results of six recent studies, comparing observed to computed water level obtained for diverse regions of the world (UK, USA, Brazil, China and the whole Europe) with different state-of-the-art models (FVCOM, Delft, Mohid, ADCIRC, SCHISM and GTSM). As usual for the water-level simulation, the mentioned models are 2D. Note that the models are diverse, utilizing different spatial discretizations. Also the horizontal resolutions are very variable, depending upon the features and extension of the focus area.

For the Sabatino et al. (2016), Veeramony et al. (2017), Ribeiro et al. (2018), Li et al. (2019) and Fernández-Montblanc et al. (2019) papers, three different stations (fifth column) were chosen for the comparison, corresponding to the sites where the simulations presented the best, the worst and intermediate results. Table 8 provides the RSME (sixth column), the NRMSE (eighth column) and, when available, the Pearson correlation (seventh column). Dullaart et al. (2020) report a comparison between simulations and observations during extreme storms; for this case results corresponding to four different storms occurring at diverse areas of the USA and the UK were chosen for the comparison of Table 8. Even though the aim of this last paper and the approach are slightly different than ours, the comparison is still interesting.

Table 8 shows that the performance can substantially vary from one to another station for the same simulation and that the diverse state of the art of forecasting and hindcasting applications present variable skills. On average, the application of FVCOM of Sabatino et al. (2016) displays the best performance, with a mean NRMSE of 4.0\%, whereas the applications of GTSM of Dullaart et al. (2020), of MOHID of Ribeiro et al. (2018), of SCHIMS of Fernández-Montblanc et al. (2019), of ADCIRC of Li et al. (2019) and of Delf of Veeramony et al. (2017), present average NRMSEs of 8.4\%, 11.5\%, 12.3\%, $14.2 \%$ and $22.3 \%$, respectively. Our application of CROCO presents average NRMSE of $8.0 \%$ for hindcast and $15 \%$ for forecast, which is lower than 5 of the 6 above mentioned. In what regards the correlation, it has been reported by only 3 of the 6 papers. Our average of 0.92 for hindcast and 0.89 for forecast are very satisfactory in the context of the international literature on the subject, as displayed by Table 8 . This way, the results support and encourage the implementation of the CROCO application presented in this article for the forecast/hindcast of storm surges in the RdP.

\section{Conclusions}

This paper presents the first step towards the development of a pre-operational forecast/hindcast modelling system for the shallow, long, wide and fast-flowing Río de la Plata (RdP) and the adjacent continental shelf. The numerical ocean model CROCO was regionalized for the area of interest. For this goal, the source code was modified to allow for 2D simulations and a subroutine was added to force the numerical model with the atmospheric surface pressure. A hierarchy of two one-way nested models forced by the tides, the atmosphere and the runoff was employed. Additionally, for the higher 


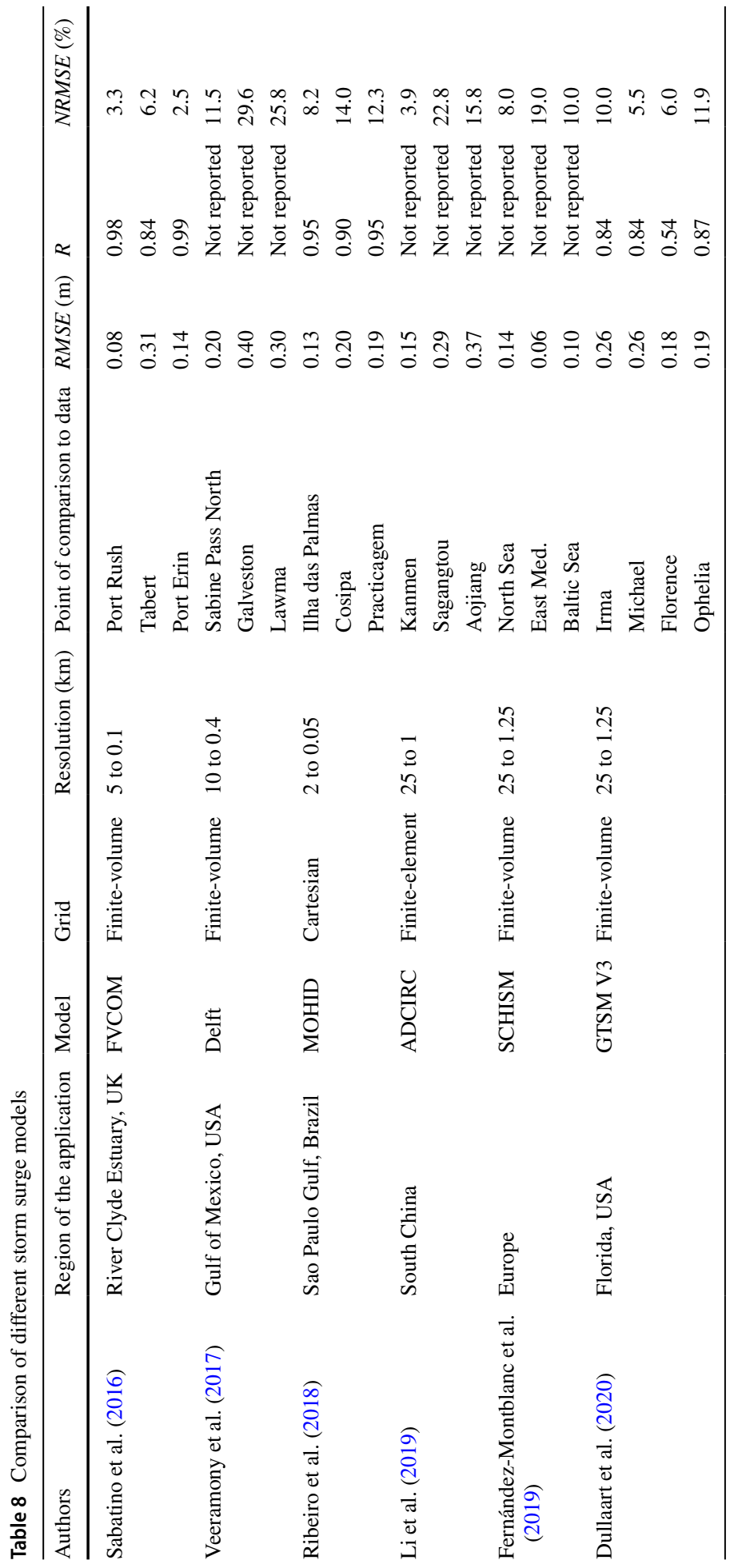


resolution model, a calibration of the wind speed through an empirical function was performed to allow for a better representation of the regional winds.

A validation of the model in hindcast mode was performed using data from tidal gauges and observations from several current meters collected at the RdP and the adjacent continental shelf. Results show that the water level and mean currents computed by the numerical model properly represent the observations with average skill scores of around 0.90 and 0.80 (being 1 for the optimal case), respectively. The model was also validated in both hindcasting and forecasting models for the ten most recent extreme positive and negative surge events (above/below $\pm 2 \mathrm{~m}$ ). Results support the good capability of the model to simulate even extreme events with average skill scores of 0.97 for the hindcast and 0.92 for the forecast modes, respectively.

This way, the forecast/hindcast model showed a skill comparable to state-of-the-art applications for other areas of the world. Even though for some events, the forecast error was about $40 \%$ with respect to the surge peak, hindcasting results were optimal. Therefore, it can be concluded that the limitations of the forecastings lie more in the forcing fields than in the oceanic numerical model, and the consideration of forcing uncertainties becomes relevant. In this sense, existing oceanic forecast systems are extending to ensemble prediction system in order to provide the user a probability forecast. This type of forecasts conveys a message which explicitly reminds the user that there is always a forecast uncertainty which should be considered during decision making. Finally, we conclude that the application of CROCO model presented in this article constitutes a useful and robust tool for the representation of water-level anomalies and transports at the RdP.

Acknowledgements This study was funded by the National Agency for Scientific and Technological Research of Argentina (ANPCyT) PICT 2014-2672 Project, the Programa de Investigación y Desarrollo para la Defensa del MINDEF (PIDDEF) 14-14 Project, and the UBACYT 20020150100118BA directed by Claudia G. Simionato. Matías G. Dinápoli participation was possible thanks to ANPCyT and CONICET PhD fellowships.

\section{Compliance with ethical standards}

Conflict of interest The authors declare that they have no conflict of interest.

\section{References}

Amante C (2009) ETOPO1 1 arc-minute global relief model : procedures, data sources and analysis. National oceanic and atmospheric administration, national environmental satellite, data, and information service, national geophysical data center, marine geology and geophysics division

Arakawa A, Lamb VR (1977) Computational design of the basic dynamical processes of the UCLA general circulation model. In: Methods in computational physics: advances in research and applications, Elsevier, pp 173-265, https://doi.org/10.1016/b978-0-12-460817-7.50009-4

Balay MA (1961) El Río de la Plata entre la Atmósfera y el Mar, publicación h-621 edn. Servicio de Hidrografía Naval, Armada Argentina, Buenos Aires

Borús J, Uriburu Quirno M, Calvo D (2008) Evaluación de caudales diarios descargados por los grandes riós del sistema del Plata al estuario del Río de la Plata. Dirección de Sistemas de Información y Alerta Hidrológico, Instituto Nacional del Agua, p 154

Bowden KF (1983) Physical oceanography of coastal waters, ellis horwood, ltd edn. Cambridge University Press, Chichester

Copernicus Climate Change Service (C3S) (2017) ERA5: Fifth generation of ECMWF atmospheric reanalyses of the global climate. Copernicus Climate Change Service Climate Data Store (CDS) https:// cds.climate.copernicus.eu/cdsapp!/home 
Campetella CM, D’Onofrio E, Cerne SB, Fiore ME, Possia NE (2007) Negative storm surges in the port of Buenos Aires. Int J Climatol 27(8):1091-1101. https://doi.org/10.1002/joc.1452

Combes V, Matano RP (2019) On the origins of the low-frequency sea surface height variability of the Patagonia shelf region. Ocean Model 142:101454. https://doi.org/10.1016/j.ocemod.2019.101454

Courant R, Friedrichs K, Lewy H (1928) Uber die partiellen differenzengleichungen der mathematischen physik. Math Ann 100:32-74

Debreu L, Marchesiello P, Penven P, Cambon G (2012) Two-way nesting in split-explicit ocean models: algorithms, implementation and validation. Ocean Model 49-50:1-21

Dinápoli MG, Simionato CG, Moreira D (2020) Model sensitivity during extreme positive and negative surges in the Río de la Plata estuary: highlighting the needs for an appropriate hindcast/forecast system. Weather Forecast. https://doi.org/10.1175/WAF-D-19-0171.1

D’Onofrio E, Fiore M, Romero S (1999) Return periods of extreme water levels estimated for some vulnerable areas of buenos aires. Continental Shelf Res 19:1681-1693. https://doi.org/10.1016/S0278 -4343(98)00115-0

D'Onofrio EE, Fiore ME, Pousa JL (2008) Changes in the regime of storm surges at Buenos Aires, Argentina. J Coastal Res 24(1,A):260-265

D'Onofrio EE, Oreiro F, Fiore ME (2012) Simplified empirical astronomical tide model: an application for the Río de la Plata estuary. Comput Geosci 44:196-202. https://doi.org/10.1016/j.cageo .2011 .09 .019

Dragani WC, Martin PB, Simionato CG, Campos MI (2010) Are wind wave heights increasing in southeastern south American continental shelf between $32^{\circ} \mathrm{s}$ and $40^{\circ} \mathrm{s}$ ? Cont Shelf Res 30(5):481-490. https://doi.org/10.1016/j.csr.2010.01.002

Dullaart JCM, Muis S, Bloemendaal N, Aerts JCJH (2020) Advancing global storm surge modelling using the new ERA5 climate reanalysis. Clim Dyn 54(1):1007-1021. https://doi.org/10.1007/s0038 2-019-05044-0

Egbert GD, Erofeeva SY (2002) Efficient inverse modeling of barotropic ocean tides. J Atmosp Ocean Technol 19(2):183-204. https://doi.org/10.1175/1520-0426(2002)019<0183:eimobo>2.0.co;2

Feng J, Li D, Li Y, Liu Q, Wang A (2018) Storm surge variation along the coast of the Bohai Sea. Sci Rep. https://doi.org/10.1038/s41598-018-29712-Z

Fernández-Montblanc T, Vousdoukas MI, Ciavola P, Voukouvalas E, Mentaschi L, Breyiannis G, Feyen L, Salamon P (2019) Towards robust pan-European storm surge forecasting. Ocean Model 133:129-144. https://doi.org/10.1016/j.ocemod.2018.12.001

Framinan MB, Etala MP, Acha EM, Guerrero RA, Lasta CA, Brown OB (1999) Physical characteristics and processes of the Río de la Plata Estuary. In: Perillo G, Piccolo M, Quivira MP (eds) Estuaries of South America: their morphology and dynamics. Springer, Berlin, pp 161-194

Gan MA, Rao VB (1991) Surface cyclogenesis over South America. Mon Weather Rev 119(5):1293-1302

Gill A (1982) Atmosphere-ocean dynamics, 1st edn. Elsevier, New York

Guerrero R, Acha M, Framinan M, Lasta C (1997) Physical oceanography of the Río de la Plata Estuary, Argentina. Cont Shelf Res 17:727-742. https://doi.org/10.1016/S0278-4343(96)00061-1

Hetland RD, Campbell L (2007) Convergent blooms of Karenia brevisalong the Texas coast. Geophys Res Lett. https://doi.org/10.1029/2007gl030474

Himschoot PH, Fernández V, Arciet J, Goldsmidt V, Fabricant J (2004) Río de la Plata and its Maritime Front environmental information system and portal: tools used and lessons learned. Inf Dev 20(4):255-258. https://doi.org/10.1177/0266666904049425

Horsburgh KJ, Wilson C (2007) Tide-surge interaction and its role in the distribution of surge residuals in the North Sea. J Geophys Res Oceans. https://doi.org/10.1029/2006JC004033

Hoyer S, Hamman J (2017) xarray: N-D labeled arrays and datasets in Python. J Open Res Softw. https:// doi.org/10.5334/jors. 148

Hussain MA, Tajima Y (2017) Numerical investigation of surge-tide interactions in the Bay of Bengal along the Bangladesh coast. Nat Hazards J Int Soc Prevent Mitig Nat Hazards 86(2):669-694

Idier D, Dumas F, Muller H (2012) Tide-surge interaction in the English Channel. Nat Hazards Earth Syst Sci 12:3709-3718. https://doi.org/10.5194/nhess-12-3709-2012

Jaime P, Menéndez A, Uriburu Quirno M, Torchio J (2002) Análisis del régimen hidrológico de los ríos Paraná y Uruguay. Informe LHA 05-216-02 Instituto Nacional del Agua, Buenos Aires, Argentina

Khalilabadi MR (2016) Tide-surge interaction in the Persian Gulf, Strait of Hormuz and the Gulf of Oman. Weather 71(10):256-261. https://doi.org/10.1002/wea.2773

Kresning B, Hashemi MR, Neill SP, Green JAM, Xue H (2019) The impacts of tidal energy development and sea-level rise in the Gulf of Maine. Energy 187:115942. https://doi.org/10.1016/j.energ y.2019.115942 
Krien Y, Dudon B, Roger J, Arnaud G, Zahibo N (2017) Assessing storm surge hazard and impact of sea level rise in the Lesser Antilles case study of Martinique. Nat Hazards Earth Syst Sci 17(9):15591571. https://doi.org/10.5194/nhess-17-1559-2017

Li T, Wang F, Hou J, Che Z, Dong J (2019) Validation of an operational forecasting system of sea dike risk in the southern Zhejiang, South China. J Oceanol Limnol 37(6):1929-1940. https://doi.org/10.1007/ s00343-019-8240-8

Luz Clara Tejedor M, Simionato CG, D’Onofrio EE, Fiore MME, Moreira D (2014) Variability of tidal constants in the Río de la Plata estuary associated to the natural cycles of the runoff. Estuar Coastal Shelf S 148(7):85-96

McKinney W (2010) Data structures for statistical computing in Python. In: van der Walt S, Millman J (eds) Proceedings of the 9th python in science conference, pp 51-56

Meccia VL, Simionato CG, Fiore ME, D’Onofrio EE, Dragani WC (2009) Sea surface height variability in the Río de la Plata estuary from synoptic to inter-annual scales: results of numerical simulations. Estuar Coast Shelf Sci 85(2):327-343. https://doi.org/10.1016/j.ecss.2009.08.024

Met Office (2010-2015) Cartopy: a cartographic python library with a matplotlib interface. Exeter, Devon, http://scitools.org.uk/cartopy

Moreira D, Simionato CG (2019) Modeling the suspended sediment transport in a very wide, shallow, and microtidal estuary, the Río de la Plata, Argentina. J Adv Model Earth Syst 11(10):3284-3304. https:// doi.org/10.1029/2018MS001605

Nicolle A, Karpytchev M, Benoit M (2009) Amplification of the storm surges in shallow waters of the Pertuis Charentais (Bay of Biscay, France). Ocean Dyn 59:921-935. https://doi.org/10.1007/s1023 6-009-0219-0

Pandey S, Rao AD (2019) Impact of approach angle of an impinging cyclone on generation of storm surges and its interaction with tides and wind waves. J Geophys Res Oceans. https://doi.org/10.1029/2019J C015433

Paul G, Ismail A, Rahman A, Karim M, Hoque A (2016) Development of tide-surge interaction model for the coastal region of Bangladesh. Estuaries Coasts. https://doi.org/10.1007/s12237-016-0110-4

Pedlosky J (1987) Geophysical fluid dynamics, 2nd edn. Springer, New York

Pousa JL, D'Onofrio EE, Fiore MME, Kruse EE (2012) Environmental impacts and simultaneity of positive and negative storm surges on the coast of the Province of Buenos Aires, Argentina. Environ Earth Sci 68(8):2325-2335. https://doi.org/10.1007/s12665-012-1911-9

Pugh D (2004) Changing sea levels: effects of tides. weather and climate. Cambridge University Press, Cambridge

Re M, Menéndez AN (2011) Modelación hidro-sedimentológica del río de la plat. dinámica de sedimentos bajo condiciones hidrometeorológicas normales. Proyecto Freplata-FFEM INA-LHA 07-296-11

Re M, Sabarots Gerbec M, Menéndez AN (2010) Modelación hidro-sedimentológica del río de la plata. implementación del modelo sedimentológico. Proyecto Freplata-FFEM INA-LHA 06-296-10

Ribeiro RB, Sampaio AFP, Ruiz MS, Leitão JC, Leitão PC (2018) First approach of a storm surge early warning system for Santos Region. In: Climate change in santos Brazil: projections, impacts and adaptation options, Springer International Publishing, pp 135-157, https://doi.org/10.1007/978-3-31996535-2_7

Sabatino AD, O'Hara Murray RB, Hills A, Speirs DC, Heath MR (2016) Modelling sea level surges in the Firth of Clyde, a fjordic embayment in south-west Scotland. Nat Hazards 84(3):1601-1623. https://doi. org/10.1007/s11069-016-2506-7

Sakamoto K, Tsujino H, Nakano H, Urakawa S, Toyoda T, Hirose N, Usui N, Yamanaka G (2019) Development of a $2-\mathrm{km}$ resolution ocean model covering the coastal seas around Japan for operational application. Ocean Dyn 69(10):1181-1202. https://doi.org/10.1007/s10236-019-01291-1

Santoro P, Fernández M, Fossati M, Cazes G, Terra R, Piedra-Cueva I (2011) Pre-operational forecasting of sea level height for the Río de la Plata. Appl Math Model 35(5):2462-2478. https://doi.org/10.1016/j. apm.2010.11.065

Saraceno M, D'Onofrio EE, Fiore ME, Grismeyer WH (2010) Tide model comparison over the Southwestern Atlantic Shelf. Cont Shelf Res 30(17):1865-1875. https://doi.org/10.1016/j.csr.2010.08.014

Sarubbi A (2007) Análisis del avance del Frente del Delta del Río Paraná. Master's thesis, Facultad de Ingeniería, Universidad de Buenos Aires

Sebastian M, Behera MR, Murty PLN (2019) Storm surge hydrodynamics at a concave coast due to varying approach angles of cyclone. Ocean Eng 191:106437. https://doi.org/10.1016/j.oceaneng.2019.106437

Seluchi ME, Saulo AC (1996) Possible mechanisms yielding an explosive cyclogenesis over South America: experiments using a limited area model. Aust Meteorl Mag 47:309-320

Shiklomanov IA (1998) A summary of the monograph world water resources. A new appraisal and assessment for the 21st Century. UNEP: Society and Cultural Organization 
SHN (1986) Mar Argentino, de Río de la Plata al Cabo de Hornos, Carta Náutica 50. Servicio de Hidrografía Naval, Armada Argentina $4^{\circ}$ ed

SHN (1992) Acceso al Río de la Plata, Carta Náutica H1. Servicio de Hidrografía Naval, Armada Argentina $5^{\circ} \mathrm{ed}$

SHN (1993) El Rincón, Golfo San Matías y Nuevo, Carta Náutica H2. Servicio de Hidrografía Naval, Armada Argentina $4^{\circ}$ ed

SHN (1999a) Río de la Plata Medio y Superior, Carta Náutica H116. Servicio de Hidrografía Naval, Armada Argentina $4^{\circ}$ ed

SHN (1999b) Río de la Plata Exterior, Carta Náutica H113,. Servicio de Hidrografía Naval, Armada Argentina $2^{\circ}$ ed

Simionato CG, Dragani WC, Meccia VL, Nuñez MN (2004a) A numerical study of the barotropic circulation of the Río de la Plata Estuary: sensitivity to bathymetry, the earth's rotation and low frequency wind variability. Estuar Coast Shelf Sci 61(2):261-273

Simionato CG, Dragani WC, Nuñez MN, Engel M (2004b) A set of 3-D nested models for tidal propagation from the Argentinian Continental Shelf to the Río de la Plata Estuary: I. M2. J Coastal Res 20(3):893-912

Simionato CG, Meccia VL, Dragani WC, Nuñez MN (2005a) Barotropic tide and baroclinic waves observations in the Río de la Plata Estuary. J Geophys Res C06008: https://doi.org/10.1029/2004JC002842

Simionato CG, Meccia VL, Dragani WC, Guerrero R, Nuñez MN (2006a) Río de la Plata estuary response to wind variability in synoptic to intraseasonal scales: Barotropic response. J Geophys Res Oceans. https://doi.org/10.1029/2005JC003297

Simionato CG, Meccia VL, Dragani WC, Nuñez MN (2006b) On the use of the NCEP/NCAR surface winds for modelling barotropic circulation in the Río de la Plata Estuary. Estuar Coast Shelf S 70:195-206

Simionato CG, Meccia VL, Guerrero R, Dragani WC, Nuñez M (2007) Río de la Plata estuary response to wind variability in synoptic to intraseasonal scales: 2 . Currents' vertical structure and its implications for the salt wedge structure. J Geophys Res 112(C7):1. https://doi.org/10.1029/2006jc003815

Sinha P, Rao Y, Dube S, Rao A, Chatterjee A (1996) Numerical investigation of tide-surge interaction in Hooghly Estuary, India. Mar Geodesy 19:235-255. https://doi.org/10.1080/01490419609388082

Veeramony J, Condon A, van Ormondt M (2017) Forecasting storm surge and inundation: model validation. Weather Forecast 32(6):2045-2063. https://doi.org/10.1175/WAF-D-17-0015.1

Virtanen P, et al. (2019) SciPy 1.0-Fundamental algorithms for scientific computing in Python. E-prints arXiv:1907.10121

van der Walt S, Colbert SC, Varoquaux G (2011) The NumPy array: a structure for efficient numerical computation. Comput Sci Eng 13(2):22-30. https://doi.org/10.1109/MCSE.2011.37

Wankang Y, Baoshu Y, Xingru F, Dezhou Y, Guandong G, Haiying C (2019) The effect of nonlinear factors on tide-surge interaction: a case study of typhoon Rammasun in Tieshan Bay, China. Estuar Coast Shelf Sci 219:420-428. https://doi.org/10.1016/j.ecss.2019.01.024

WMO (2011) World Meteorological Organization-Guide to storm surge forecasting. Cambridge University Press, http://hdl.handle.net/11329/393

Xiong M, Zhang J, Zhang W, Yin C (2019) Heterogeneous tide-surge interaction during co-occurrence of tropical and extratropical cyclones in the radial sand ridges of the southern Yellow Sea. J Oceanol Limnol 37(6):1879-1898. https://doi.org/10.1007/s00343-019-8264-0

Xu J, Zhang YH, Cao AZ, Liu Q, Lv XQ (2016) Effects of tide-surge interactions on storm surges along the coast of the Bohai Sea, Yellow Sea, and East China Sea. Sci China Earth Sci 59(6):1308-1316. https:// doi.org/10.1007/s11430-015-5251-y

Zhang WZ, Shi F, Hong HS, Shang SP, Kirby JT (2010) Tide-surge interaction intensified by the Taiwan Strait. J Geophys Res. https://doi.org/10.1029/2009JC005762

Zhang X, Marta-Almeida M, Hetland HR (2012) A high-resolution pre-operational forecast model of circulation on the Texas-Louisiana continental shelf and slope. J Oper Oceanogr 5(1):19-34. https://doi. org/10.1080/1755876X.2012.11020129

Publisher's Note Springer Nature remains neutral with regard to jurisdictional claims in published maps and institutional affiliations. 


\section{Affiliations}

\section{Matías G. Dinápoli ${ }^{1,2,3}$ C Claudia G. Simionato ${ }^{1,2,3,4} \cdot$ Diego Moreira $^{1,2,3,4}$}

$\triangle$ Matías G. Dinápoli

matias.dinapoli@cima.fcen.uba.ar

1 Facultad de Ciencias Exactas y Naturales, Universidad de Buenos Aires, Intendente Güiraldes 2160 - Ciudad Universitaria - Pabellón 2, Buenos Aires, Argentina

2 Centro de Investigaciones del Mar y la Atmósfera (CIMA), CONICET - Universidad de Buenos Aires, Intendente Güiraldes 2160 - Ciudad Universitaria - Pabellón 2, Buenos Aires, Argentina

3 Instituto Franco-Argentino para el Estudio del Clima y sus Impactos (UMI 3351 IFAECI), CNRS - IRD - CONICET - UBA, Intendente Güiraldes 2160 - Ciudad Universitaria - Pabellón 2, Buenos Aires, Argentina

4 Departamento de Ciencias de la Atmósfera y los Océanos, FCEN, Universidad de Buenos Aires, Intendente Güiraldes 2160 - Ciudad Universitaria - Pabellón 2, Buenos Aires, Argentina 